\title{
A Synthetic Isoprenoid Lipoquinone, Menaquinone-2, Adopts a Folded Conformation in Solution and at a Model Membrane Interface
}

\author{
Jordan T. Koehn, ${ }^{\dagger}$ Estela S. Magallanes, ${ }^{\dagger}$ Benjamin J. Peters, ${ }^{\dagger}$ Cheryle N. Beuning, ${ }^{\dagger}$ Allison A. Haase, ${ }^{\dagger}$ \\ Michelle J. Zhu, ${ }^{\dagger}$ Christopher D. Rithner, ${ }^{\dagger}$ Dean C. Crick, ${ }^{\ddagger}{ }^{\circ}$ and Debbie C. Crans ${ }^{*}, \dagger, \neq 0$ \\ ${ }^{\dagger}$ Chemistry Department, ${ }^{\ddagger}$ Cell and Molecular Biology Program, and ${ }^{\S}$ Microbiology, Immunology, and Pathology Department, \\ Colorado State University, Fort Collins, Colorado 80523, United States
}

\section{Supporting Information}

ABSTRACT: Menaquinones (naphthoquinones, MK) are isoprenoids that play key roles in the respiratory electron transport system of some prokaryotes by shuttling electrons between membrane-bound protein complexes acting as electron acceptors and donors. Menaquinone-2 (MK-2), a truncated MK, was synthesized, and the studies presented herein characterize the conformational and chemical properties of the hydrophobic MK-2 molecule. Using 2D NMR spectroscopy, we established for the first time that MK-2 has a folded conformation defined by the isoprenyl sidechain folding back over the napthoquinone in a U-shape, which depends on the specific environmental conditions found in different solvents. We used molecular mechanics to illustrate conformations found by the NMR experiments. The measured redox potentials of MK-2 differed in three organic solvents, where MK-2 was most easily reduced in DMSO, which may suggest a combination of solvent effect (presumably in part because of differences in dielectric constants) and/or conformational differences of MK-2 in different organic solvents. Furthermore, MK-2 was found to associate with the interface of model membranes represented by Langmuir phospholipid monolayers and Aerosol-OT (AOT) reverse micelles. MK-2 adopts a slightly different U-shaped conformation within reverse micelles compared to within solution, which is in sharp contrast to the extended conformations illustrated in literature for MKs.

\section{INTRODUCTION}

Isoprenoids are among the most numerous and diverse compounds found in nature. ${ }^{1-3}$ It was reported that 55,000 of these naturally occurring compounds had been identified by $2007 ;^{3}$ an estimate that increased to 70,000 in $2015 .{ }^{1}$ Classes of isoprenoids include lipoquinones, sterols, carotenoids, prenylated proteins, dolichols, monoterpenes, and sesquiterpenes. These compounds are involved in diverse functions such as electron transport, hormone function, membrane structure and fluidity, vision, photoprotection, insect reproduction, fragrance, and defense. The solution structures of many of these compounds, such as the sterols, are well studied. However, the conformations of long linear polymers of isoprene units such as those found in the side-chains of lipoquinones involved in bacterial and eukaryotic electron transport systems (ETS) have not been characterized. ${ }^{4-7}$ Lipoquinones are small hydrophobic molecules that shuttle electrons between the membrane-bound protein complexes acting as electron acceptors and donors in the respiratory ETS. Two major structural groups of lipoquinones are recognized: ubiquinones (or benzoquinones, UBQ) typically found in eukaryotes and Gram-negative prokaryotes and menaquinones (or naphthoquinones, MK) typically found in Gram-positive prokaryotes, including many pathogens such as Mycobacterium tuberculosis. The roles and applications of lipoquinone derivatives are currently being explored where a range of different approaches are used for combatting human diseases. $^{8-20}$ This manuscript aims to characterize the conformation of a synthetic truncated $\mathrm{MK}$ analog within organic solutions and within a model membrane interface as well as document the redox potential of these systems accompanying the conformational studies.

Here, we use an abbreviation system where MK with two isoprene units is MK-2 and with nine isoprene units is MK-9, Figure 1 . Naturally occurring lipoquinones are characterized by the presence of an isoprenyl side-chain of varying length from 1 to 14 isoprene units ${ }^{21,22}$ depending on the species of origin; a characteristic long used to assist taxonomic efforts. Textbooks often represent UBQ and $M K$ as "Q" or "MQ" in illustrations of the ETS, and in primary literature they are generally shown in an extended conformation, Figure 1. ${ }^{7,23,24}$ The extended conformation of these molecules seems highly unlikely in light of the one-step cyclization of squalene epoxide, an isoprenoid compound containing six isoprene units, to form the protosterol cation, which contains the basic steroidal ring system with eight chiral centers. ${ }^{25,26}$ Woodward reported the cyclization of this

Received: October 18, 2017

Published: November 23, 2017 
<smiles>C=C(C=CC(C)(C)CC(C)=CCCC(C)=CCC1=C(C)C(=O)c2ccccc2C1=O)[Te]=[In]</smiles>

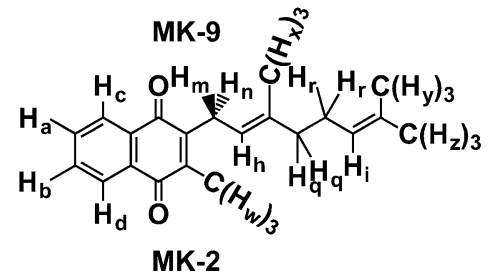

Figure 1. Structure of menaquinone-9 (MK-9), a representative MK found in Mycobacterium tuberculosis (top) and MK-2, a simplified MK analog (bottom), is also shown. Protons are labeled on MK-2 for spectral interpretation.

polyisoprenoid squalene epoxide forming only one stereoisomer out of the possible $256\left(2^{8}\right)$ in $1953 .^{25,26}$ The stereospecificity of this reaction requires preorganization of the epoxide before protonation, and such a conformer is not the extended conformation commonly depicted in the literature.

Small angle X-ray diffraction experiments with the isoprenoid dolichol, an alcohol with 18-20 isoprene units, indicated that the molecule adopted a helical structure in organic solvent. ${ }^{27}$ The conformation of the isoprenoid moiety in MK derivatives is likely important to its function as an electron-transfer agent and other biological roles. Although nothing is known about the conformation of MK derivatives, limited conformational analysis is available on different classes of compounds including alkanes, alkenes, and fatty acids with much simpler structures. ${ }^{28-42}$ The all-trans conformations of alkanes are generally considered the most stable, and therefore, it is expected that the most prevalent conformation of an alkane is the fully extended alkyl chain. ${ }^{28} \mathrm{~A}$ few studies have been reported with simple alkanes and a range of other, more complex compounds with large alkane-components such as in polyenes and fatty acids. ${ }^{29,30}$ The U-shape in fatty acids was described when bound to a fatty acid binding protein (FABP), where the alkyl chain region of two fatty acids, palmitic and oleic acids, folds over in the shape of a U. ${ }^{39,40}$ In 2008, X-ray crystal structure analysis, as well as NMR spectroscopy, also supported the U-shaped conformation of amphiphilic alkyl chains bound to a synthetic receptor where the folded $\mathrm{C}_{8}, \mathrm{C}_{10}$, and $\mathrm{C}_{12}$ conformations have anticlinal as well as gauche arrangements. ${ }^{39,40}$ Based on these few examples, we hypothesized that MKs will adopt folded conformations depending on specific environmental conditions.

In this manuscript, we describe the synthesis and characterization of a truncated MK derivative with two isoprene units. MK-2 (Figure 1) can be characterized in detail and serves as a representative $\mathrm{MK}$ reference compound as it is the simplest MK containing a napthoquinone and repeating isoprenyl side-chain allowing comparison to more complex MK-derivatives found in various microorganisms. ${ }^{6,43,44}$ First, the conformation of MK-2 was investigated in organic solvents (polar and hydrophobic). Next, because we are ultimately interested in the function of these derivatives, we measured the electrochemical potential of MK-2 in the organic solvents where the conformations were determined. Finally, the location and conformation of MK-2 in simple membrane model systems was examined. Combined, our results show that MK-2 folds into a U-shaped conformation in solution contrary to common perception and that a folded, slightly different U-shaped conformation also exists in the presence of a simple model lipid membrane interface.

\section{RESULTS AND DISCUSSION}

Synthesis of MK-2. MK-2 was synthesized using a procedure in literature (Scheme 1). ${ }^{45,46}$ First, menadione 1 was reduced to the corresponding menadiol 2 using aqueous sodium dithionite. Geraniol 3 was coupled to menadiol 2 using the Lewis acid catalyst, boron trifluoride. This preparation produced a yield of $20 \%$ overall, which is lower than the reported MK-2 preparation with the deuterated analog in literature. ${ }^{45}$ The lower yield appears to be due to extensive alkylation at the $\mathrm{C} 2$ position instead of the desired C3 position; however, this side product is readily separated using column chromatography. Highly pure material yields a yellow solid upon crystallization at $-20^{\circ} \mathrm{C}$ and retains this state when warmed to room temperature, while material with impurities does not crystallize and remains a red oil.

1D ${ }^{1} \mathrm{H}$ NMR Spectroscopic Studies of MK-2 in Different Solvents. MK-2 was first characterized using $1 \mathrm{D}{ }^{1} \mathrm{H}$ NMR spectroscopy. Figure 2 shows ${ }^{1} \mathrm{H}$ NMR spectra of MK-2 in isooctane (2,2,4-trimethylpentane), $d_{5}$-pyridine, $d_{6}$-benzene, $d_{3}$ acetonitrile, $d_{6}$-DMSO, and $\mathrm{D}_{2} \mathrm{O}$. The observed chemical shifts of MK-2 vary dramatically in the different solvents shown. Hydrophobic solvent environments including aliphatic (isooctane) and aromatic ( $d_{5}$-pyridine and $d_{6}$-benzene) as well as hydrophilic $\left(d_{3}\right.$-acetonitrile, $d_{6}$-DMSO, and $\left.\mathrm{H}_{2} \mathrm{O} / \mathrm{D}_{2} \mathrm{O}\right)$ solvent environments generate very different spectroscopic signatures. For example, the pairs of aromatic protons, $\mathrm{H}_{\mathrm{a}} / \mathrm{H}_{\mathrm{b}}$ and $\mathrm{H}_{\mathrm{c}} / \mathrm{H}_{\mathrm{d}}$, are significantly different in the two different classes of solvents. This observed variation in chemical shift could be attributed to conformational changes of MK-2 in the various solvent environments investigated, alterations of the electronic state due to interaction with the solvent, or most likely, a combination of both. Focusing on the ${ }^{1} \mathrm{H}$ NMR spectra of MK-2 in the three hydrophilic solvents, $d_{3}$-acetonitrile, $d_{6}$-DMSO, and $\mathrm{D}_{2} \mathrm{O}$, some differences and similarities are observed (Figure 2). The MK-2 spectrum in $\mathrm{D}_{2} \mathrm{O}$ required significantly more scans to produce a reasonable spectrum because of the poor solubility in $\mathrm{D}_{2} \mathrm{O}$. The

Scheme 1. Synthetic Route To Prepare MK-2 4 from Menadiol 2 and Geraniol 3 using Lewis Acid Catalyst Conditions ${ }^{45,46}$

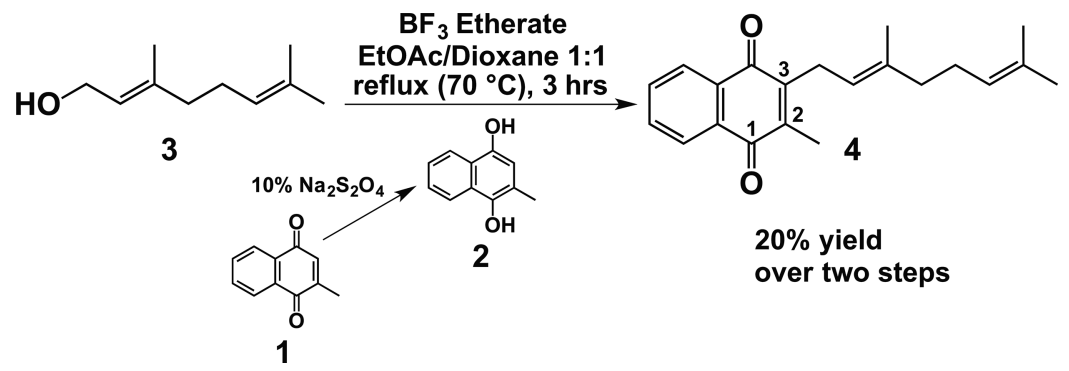




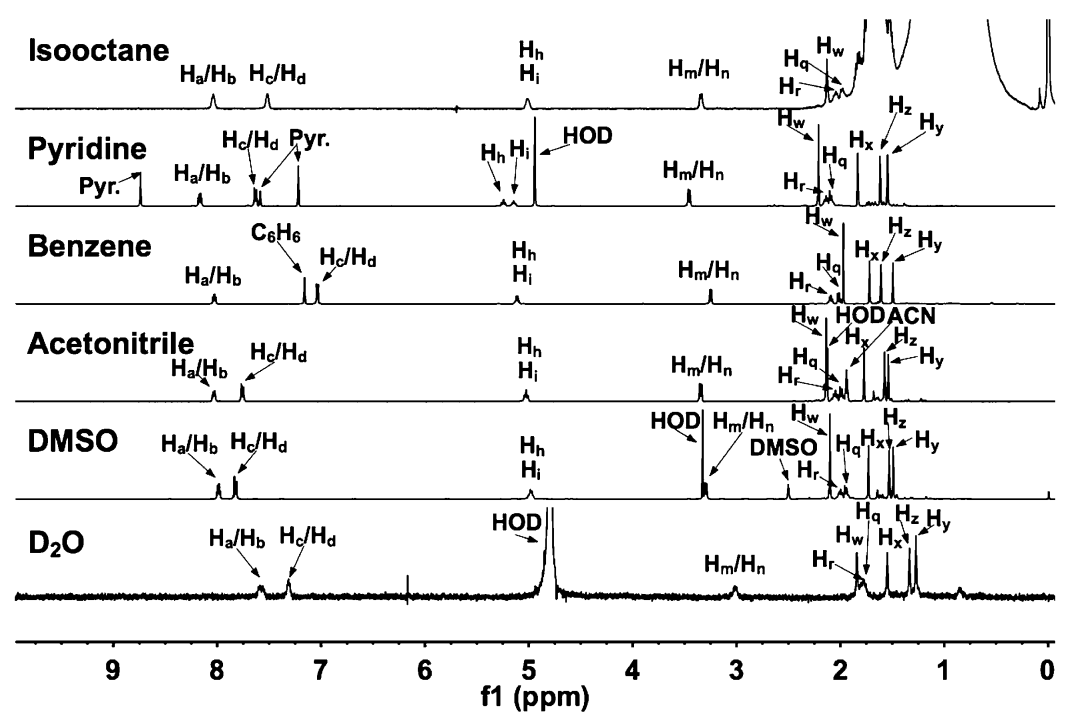

Figure 2. $1 \mathrm{D}{ }^{1} \mathrm{H}$ NMR $(400 \mathrm{MHz})$ spectra of MK-2 in hydrophilic $\left(d_{6}\right.$-DMSO, $d_{3}$-acetonitrile, and $\left.\mathrm{D}_{2} \mathrm{O}\right)$ and hydrophobic [isooctane $(2,2,4$ trimethtylpentane), $d_{5}$-pyridine, and $d_{6}$-benzene] solvents. Proton peak text labeling corresponds to MK-2 structure in Figure 1.

proton chemical shifts generally are observed further upfield in $\mathrm{D}_{2} \mathrm{O}$, presumably indicative of more aggregation in this solvent. The alkene $\mathrm{H}_{h}$ and $\mathrm{H}_{\mathrm{i}}$ proton signals are not observed in the $\mathrm{D}_{2} \mathrm{O}$ spectrum because of overlap with the HOD peak. However, the HOD signal in the $d_{6}$-DMSO spectrum is observed at $3.3 \mathrm{ppm}$, which allows for observation of the alkene protons, $\mathrm{H}_{\mathrm{h}}$ and $\mathrm{H}_{\mathrm{i}}$, at $4.9 \mathrm{ppm}$. The spectrum of MK-2 in $d_{6}$-DMSO is very similar to that in $d_{3}$-acetonitrile, and both also have some similarities to the MK-2 spectrum in $\mathrm{D}_{2} \mathrm{O}$. The aromatic protons, $\mathrm{H}_{\mathrm{a}} / \mathrm{H}_{\mathrm{b}}$, shifted about $0.2 \mathrm{ppm}$ from the $\mathrm{H}_{\mathrm{c}} / \mathrm{H}_{\mathrm{d}}$ signals in both solvents. This suggests that these protons remain in similar chemical environments in these two solvent environments. Combined, these three spectra provide a representation of the properties of the MK-2 in a hydrophilic solvent environment.

Next, the aromatic and alkene protons were examined in the hydrophobic solvents, isooctane, $d_{5}$-pyridine, and $d_{6}$-benzene (Figure 2). Here, protons $\mathrm{H}_{a}, \mathrm{H}_{\mathrm{b}}, \mathrm{H}_{c}, \mathrm{H}_{\mathrm{d}}, \mathrm{H}_{\mathrm{h}}$, and $\mathrm{H}_{\mathrm{i}}$ are observed and readily identified. The signals from alkene protons, $\mathrm{H}_{h}$ and $\mathrm{H}_{\mathrm{i}}$, are both further downfield compared to the signals in hydrophilic solvents, and most interestingly, the two alkene protons become nonchemical shift equivalent in $d_{5}$-pyridine. This contrasts with the aliphatic protons in the spectrum in $d_{6^{-}}$ benzene, which are like those in $d_{6}$-DMSO except for $\mathrm{H}_{q}, \mathrm{H}_{\mathrm{r}}, \mathrm{H}_{\mathrm{w}}$, and $\mathrm{H}_{\mathrm{z}}$. The changes in the chemical shifts are most distinctive in the aromatic and alkene protons, suggesting that there are some major differences in their respective environments. Together, these differences strongly indicate that MK-2 is sensitive to the solvent environment. However, information from 2D NMR experiments is needed to elucidate if this change in chemical shift is due to conformational variations and/or solvent effect.

\section{${ }^{1} \mathrm{H}-{ }^{1} \mathrm{H}$ 2D NOESY and ${ }^{1} \mathrm{H}-{ }^{1} \mathrm{H}$ 2D ROESY NMR} Spectroscopic Studies of MK-2 in $d_{6}$-DMSO and $d_{5}$ Pyridine. Differences between the conformations observed in $d_{6}$-DMSO vs $d_{5}$-pyridine are likely manifested by the conformation minimizing the unfavorable interactions with the solvent environment and maximizing favorable intramolecular interactions with the isoprenyl side-chain. To investigate the conformation of MK-2 in organic solvents, we utilized two different but complementary $2 \mathrm{D}$ NMR methods, ${ }^{1} \mathrm{H}-{ }^{1} \mathrm{H} 2 \mathrm{D}$ NOESY and ${ }^{1} \mathrm{H}-{ }^{1} \mathrm{H} 2 \mathrm{D}$ ROESY. Figure 3 shows the ${ }^{1} \mathrm{H}-{ }^{1} \mathrm{H} 2 \mathrm{D}$ NOESY and ROESY NMR spectra of MK-2 in $d_{6}$-DMSO and portions of the spectrum in $d_{5}$-pyridine. Figure $3 \mathrm{~A}$ shows the complete ${ }^{1} \mathrm{H}-{ }^{1} \mathrm{H} 2 \mathrm{D}$ NOESY spectrum of MK-2 in $d_{6}$-DMSO and Figure $3 \mathrm{~B}-\mathrm{C}$ shows zoomed in regions of interest in the NOESY and ROESY spectra collected in $d_{6}$-DMSO, respectively (see Figures S3-S4 for full spectra). Figure 3D-F shows zoomed in regions of interest in the NOESY and ROESY spectra collected in $d_{5}$-pyridine, respectively (see Figures $S 6-S 7$ for full spectra). Figure 3B,D illustrates that MK-2 alkene protons, $\mathrm{H}_{h}$ and $\mathrm{H}_{\mathrm{i}}$, are in similar environments in $d_{5}$-pyridine and $d_{6}$-DMSO due to the observance of similar NOE cross peaks. In both solvents, Figure 3B,D shows NOE cross peaks illustrating that $\mathrm{H}_{\mathrm{h}}$ and $\mathrm{H}_{\mathrm{i}}$ interact with $\mathrm{H}_{\mathrm{n}} / \mathrm{H}_{\mathrm{m}}, \mathrm{H}_{\mathrm{q}}, \mathrm{H}_{\mathrm{r}}$, and $\mathrm{H}_{\mathrm{z}}$. Figure $3 \mathrm{~B}, \mathrm{D}$ shows NOE cross peaks demonstrating proton $\mathrm{H}_{\mathrm{w}}$ interacts with protons $\mathrm{H}_{\mathrm{h}} / \mathrm{H}_{\mathrm{i}}$ and $\mathrm{H}_{\mathrm{m}} / \mathrm{H}_{\mathrm{n}}$ in both $d_{6}$-DMSO and $d_{5}$-pyridine. Figure $3 \mathrm{C}$,E shows partial ${ }^{1} \mathrm{H}-{ }^{1} \mathrm{H}$ 2D ROESY NMR spectra where the focus is on proton $\mathrm{H}_{\mathrm{w}}$ in $d_{6}$-DMSO and $d_{5}$-pyridine (see Figures S4 and S7 for full spectra and Figure S9 for NOE/ ROE correlation traces (slices)). Figure $3 \mathrm{~B}-\mathrm{C}$ shows partial spectra for MK-2 in $d_{6}$-DMSO, where NOE and ROE cross peaks indicate the $\mathrm{H}_{\mathrm{w}}$ proton interacts with $\mathrm{H}_{\mathrm{q}}, \mathrm{H}_{\mathrm{r}}, \mathrm{H}_{\mathrm{x}}$ and $\mathrm{H}_{\mathrm{y}}$. However, the lack of ROE cross peaks in Figure $3 \mathrm{E}$ shows $\mathrm{H}_{\mathrm{w}}$ does not interact with $\mathrm{H}_{\mathrm{y}}$ or $\mathrm{H}_{\mathrm{z}}$ in $d_{5}$-pyridine (observed cross peaks between $\mathrm{H}_{\mathrm{w}}$ and $\mathrm{H}_{\mathrm{y}}$ or $\mathrm{H}_{\mathrm{z}}$ in $d_{5}$-pyridine are likely due to TOCSY exchange). The observation of cross peaks shows that there are similar interactions between the aromatic and alkene protons in the two solvents; however, there is a twist around the $\mathrm{C}-\mathrm{C}$ bond leading to closer proximity of the $\mathrm{H}_{\mathrm{w}}$ with the $\mathrm{H}_{\mathrm{q}}, \mathrm{H}_{\mathrm{r}}$, $\mathrm{H}_{x}$, and $\mathrm{H}_{\mathrm{y}}$ protons in $d_{6}$-DMSO. The NOE and ROE cross peaks in the $d_{6}$-DMSO spectrum in Figure 3 clearly support a folded, Ushaped conformation for MK-2 in $d_{6}$-DMSO. However, evidence of a folded conformation for MK-2 is not as definitive in $d_{5}$ pyridine due to the lack of NOE and ROE cross peaks between $\mathrm{H}_{\mathrm{w}}$ and $\mathrm{H}_{\mathrm{y}}$ or $\mathrm{H}_{\mathrm{z}}$. If $\mathrm{MK}-2$ did adopt a U-shaped conformation in $d_{5}$-pyridine, it would have a conformation as shown in Figure $4 \mathrm{~B}$, where the distance between $\mathrm{H}_{\mathrm{w}}$ and $\mathrm{H}_{\mathrm{y}} / \mathrm{H}_{\mathrm{z}}$ is beyond observation in the ${ }^{1} \mathrm{H}-{ }^{1} \mathrm{H} 2 \mathrm{D}$ NOESY and ROESY NMR experiment. This conformation for MK-2 in $d_{5}$-pyridine is based on other NOE/ ROE cross peaks observed (i.e., $\mathrm{H}_{\mathrm{w}}$ to $\mathrm{H}_{\mathrm{h}}, \mathrm{H}_{\mathrm{w}}$ to $\mathrm{H}_{\mathrm{q}}$ or $\mathrm{H}_{\mathrm{r}}, \mathrm{H}_{\mathrm{w}}$ to $\mathrm{H}_{x}$ ). Figure $3 \mathrm{~F}$ illustrates $\pi-\pi$ stacking between pyridine and part of the napthoquinone ring, which could possibly explain the lack of interaction between $\mathrm{H}_{\mathrm{w}}$ and $\mathrm{H}_{\mathrm{y}}$ or $\mathrm{H}_{\mathrm{z}}$. 
(A) Full NOESY $d_{6}$-DMSO

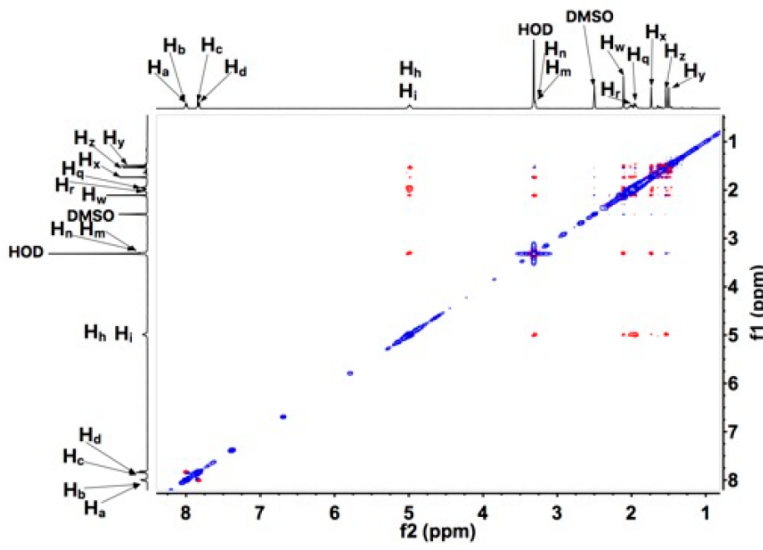

(C) Partial ROESY $d_{6}$-DMSO

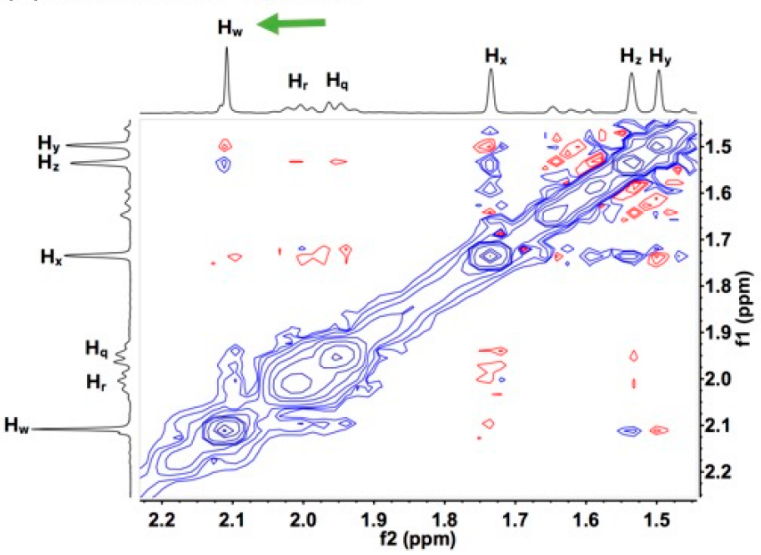

(E) Partial ROESY $d_{5}$-Pyridine

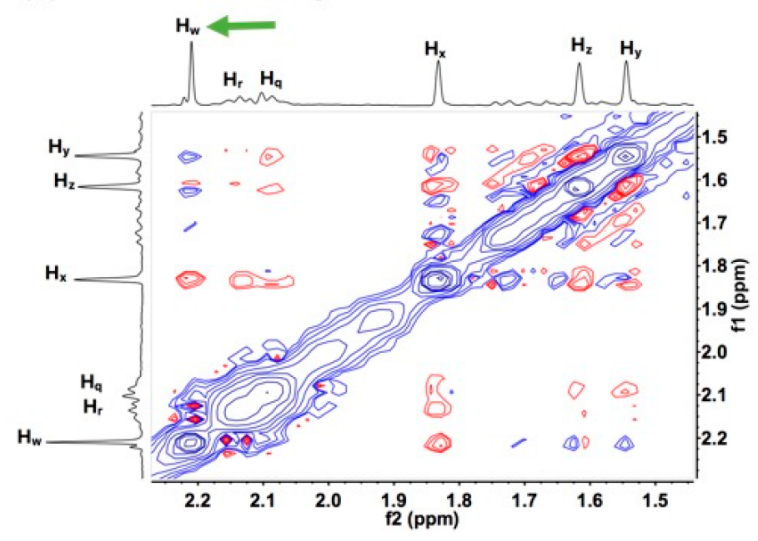

(B) Partial NOESY $\mathrm{d}_{6}$-DMSO

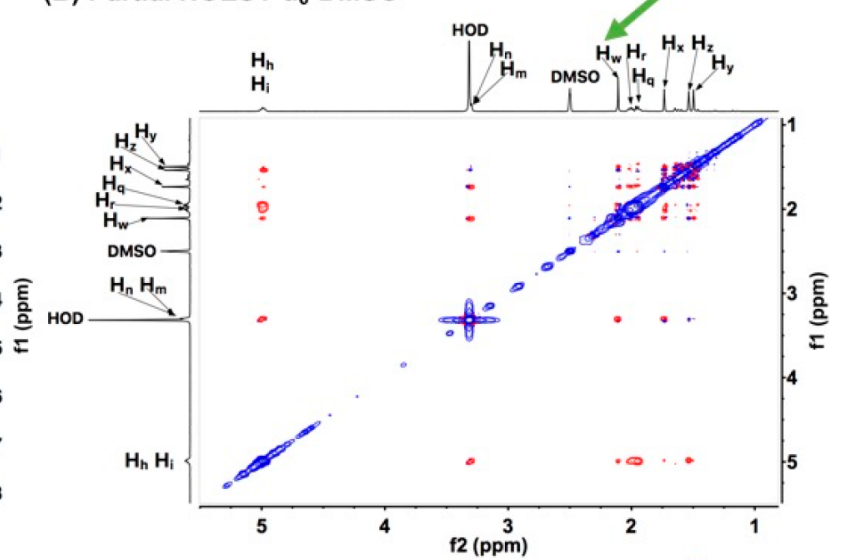

(D) Partial NOESY $d_{5}$-Pyridine

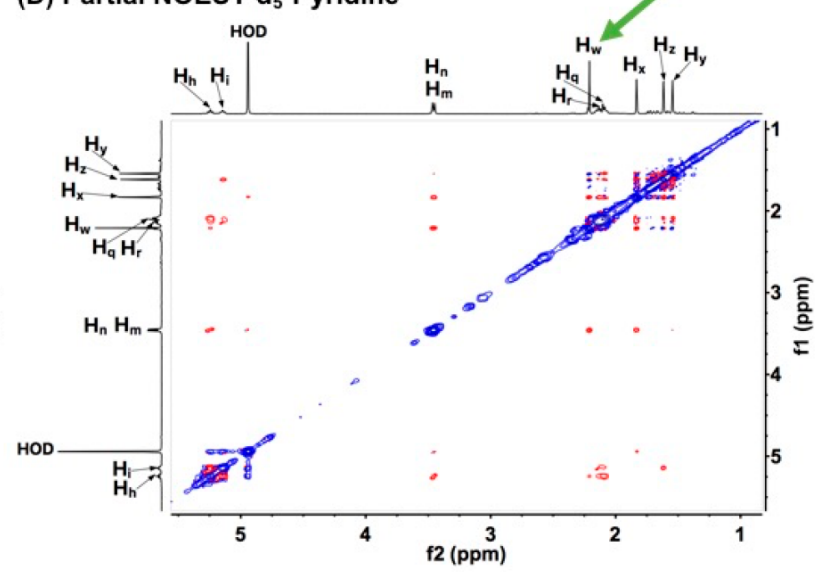

(F) Partial NOESY $d_{5}$-Pyridine

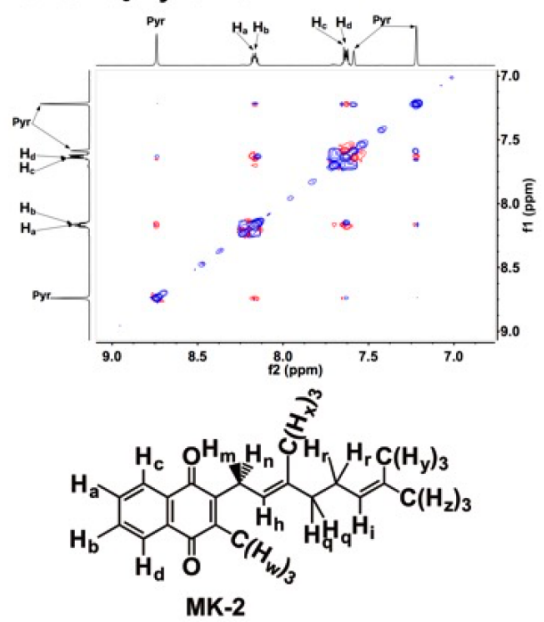

Figure 3. ${ }^{1} \mathrm{H}-{ }^{1} \mathrm{H} 2 \mathrm{D}$ NOESY and ${ }^{1} \mathrm{H}-{ }^{1} \mathrm{H} 2 \mathrm{D}$ ROESY NMR (400 MHz) spectra of $20 \mathrm{mM} \mathrm{MK}-2$ in $d_{6}$-DMSO and $d_{5}$-pyridine at $26{ }^{\circ} \mathrm{C}$. (A) Full ${ }^{1} \mathrm{H}-{ }^{1} \mathrm{H} 2 \mathrm{D}$ NOESY NMR spectrum of MK-2 in $d_{6}$-DMSO. (B) Partial ${ }^{1} \mathrm{H}-{ }^{1} \mathrm{H} 2 \mathrm{D}$ NOESY NMR spectrum of MK-2 in $d_{6}$-DMSO. (C) Partial ${ }^{1} \mathrm{H}-{ }^{1} \mathrm{H}$ 2D ROESY NMR spectrum of MK-2 in $d_{6}$-DMSO. (D) Partial ${ }^{1} \mathrm{H}-{ }^{1} \mathrm{H} 2 \mathrm{D}$ NOESY NMR spectrum of MK-2 in $d_{5}$-pyrdine. (E) Partial ${ }^{1} \mathrm{H}-{ }^{1} \mathrm{H} 2 \mathrm{D}$ ROESY NMR spectrum of MK-2 in $d_{5}$-pyrdine. (F) Partial ${ }^{1} \mathrm{H}-{ }^{1} \mathrm{H} 2 \mathrm{D}$ ROESY NMR spectrum of MK-2 in $d_{5}$-pyridine illustrating stacking interactions. Blue intensity contours represent negative NOE's or ROE's, and red intensity contours represent positive NOE's or ROE's. A standard NOESY pulse sequence was used consisting of 200-256 transients with 16 scans in the f1 domain using a $500 \mathrm{~ms}$ mixing time and a $1.5 \mathrm{~s}$ relaxation delay. A standard ROESYAD pulse sequence was used consisting of 200 or 256 transients with 16 scans in the f1 domain using a $400 \mathrm{~ms}$ mixing time and a $2.0 \mathrm{~s}$ relaxation delay. The structure of MK- 2 is shown with a proton labeling scheme key. Green arrows indicate proton $\mathrm{H}_{\mathrm{w}}$, where the observed cross peaks differed the most between the two solvents studied.

Illustrating MK-2 Conformations using Molecular Mechanics. MK-2 has a short repeating isoprenyl chain $\left(\mathrm{C}_{10}\right)$ but contains enough carbons to produce numerous degrees of rotational freedom; therefore, even the truncated version of $\mathrm{MK}$,
MK-2, can assume many different conformations. Using molecular mechanics calculations, we explored the energy surface and visualized specific conformations defined by the ${ }^{1} \mathrm{H}-{ }^{1} \mathrm{H} 2 \mathrm{D}$ NOESY and ROESY NMR experiments of MK-2 in 
(A)

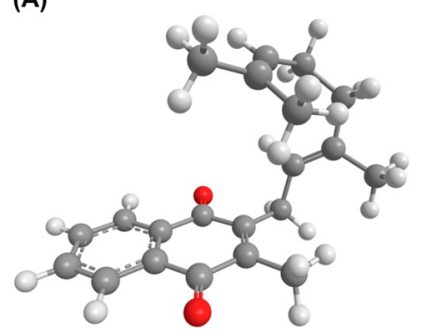

(B)

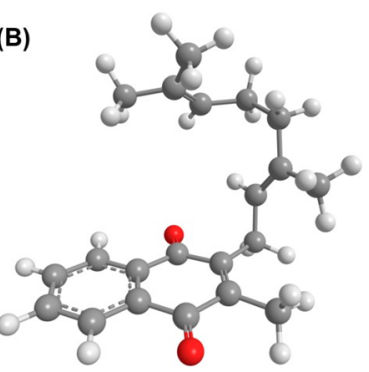

Figure 4. MK-2 conformations generated using MMFF94 calculations to illustrate the conformations elucidated by the 2D NMR studies. (A) Illustrates the MK-2 conformation in $d_{6}$-DMSO determined from ${ }^{1} \mathrm{H}-{ }^{1} \mathrm{H}$ 2D NOESY and ROESY NMR spectral data cross peak interactions $\left(66.8 \mathrm{kcal} / \mathrm{mol}\right.$, and internuclear distance $\left.\mathrm{H}_{\mathrm{w}}-\mathrm{H}_{\mathrm{y}}: 2.6 \AA\right)$. (B) Illustrates a potential U-shaped MK-2 conformation in $d_{5}$-pyridine consistent with the ${ }^{1} \mathrm{H}-{ }^{1} \mathrm{H} 2 \mathrm{D}$ NOESY and ROESY NMR spectral data cross peak interactions $\left(66.7 \mathrm{kcal} / \mathrm{mol}\right.$, and internuclear distance $\mathrm{H}_{\mathrm{w}}-$ $\mathrm{H}_{\mathrm{y}}: 6.1 \AA ̊$ ). See Supporting Information for a table of selected proton to proton distances for conformations $\mathrm{A}$ and $\mathrm{B}$.

$d_{6}$-DMSO and $d_{5}$-pyridine. Specific conformations were generated based on distances imposed by the NMR data and then energy optimized to produce realistic bond lengths and angles for these conformations. Finally, an energy was calculated to ensure that the conformation was at a reasonable energy. Longer calculations generally lead to rotations around bonds and conformations not exactly as those suggested from the NMR data (see below and Supporting Information). The intent with the molecular mechanics calculations was to illustrate conformations corresponding to the ${ }^{1} \mathrm{H}-{ }^{1} \mathrm{H}$ 2D NOESY and ROESY NMR spectral data in $d_{6}$-DMSO and $d_{5}$-pyridine constrained by all cross peak interactions observed as well as to provide visual aids (Figure 4). One of the low-energy conformations generated for MK-2 has a conformation (Figure 4A, $66.8 \mathrm{kcal} / \mathrm{mol}, \mathrm{H}_{\mathrm{w}}-\mathrm{H}_{\mathrm{y}}: 2.6$ A) consistent with the 2D NOESY and ROESY spectral parameters observed in $d_{6}$-DMSO. Figure 4B illustrates a potential conformation of MK-2 that is consistent with the $2 \mathrm{D}$ NOESY and ROESY spectral parameters observed in $d_{5}$-pyridine (66.7 kcal $\left./ \mathrm{mol}, \mathrm{H}_{\mathrm{w}}-\mathrm{H}_{\mathrm{y}}: 6.1 \AA \AA\right)$. See Table $\mathrm{S} 1$ for selected proton to proton distances for conformations seen in Figure $4 \mathrm{~A}-\mathrm{B}$ consistent with the 2D NOESY and ROESY NMR spectral parameters. The MK-2 conformation determined in $d_{6}$-DMSO adopts a folded, U-shaped conformation.

Fewer NOE and ROE cross peaks were observed in $d_{5^{-}}$ pyridine that would indicate a folded conformation, and although this does not preclude a U-shaped conformation, it does suggest that the $\mathrm{H}_{\mathrm{w}}-\mathrm{H}_{\mathrm{y}}$ internuclear distance is longer and outside the observable range using the ${ }^{1} \mathrm{H}-{ }^{1} \mathrm{H} 2 \mathrm{D}$ NOESY and ROESY NMR experiment. We based this folded conformation off other NOE and ROE cross peaks observed, which were suggestive of folding (see Figure 3 and related discussion). However, a Ushaped conformation has been observed by NMR analysis in another aromatic solvent, $d_{6}$-benzene, for $n$-dodecane. ${ }^{34}$ The $\mathrm{U}$ shaped conformations shown in Figure 4 are representative of many possible stable conformations MK-2 could adopt. For comparison, Figure S12C shows another favorable conformation for MK-2 that has a characteristic U-shape. The energy of the conformation C shown in Figure S12C was the lowest energy we found. This conformation was obtained by subjecting an extended MK-2 conformation to 10,000 iterations followed by an energy minimization, illustrating that nonextended conformations are readily reached and energetically favorable.

Combined, the stability of the U-shaped conformations shown by these simple calculations is in line with work reported that showed ${ }^{1} \mathrm{H}$ NMR spectra of $n$-pentane and $n$-hexane measured in polar and spherical solvents such as DMSO favor gauche conformations as well as the reported U-shaped conformations of alkyl chains bound to synthetic receptors. ${ }^{39,40,47}$ The folded conformations for MK-2 demonstrated herein from experiments align with reported computationally determined conformations for MK analogs. ${ }^{48}$ However, it is contrary to the general expectation that the all-trans conformations of alkanes or alkyl components are the most stable. ${ }^{7,23,24,28}$

In addition to the U-shaped conformations seen in conformations A and B in Figure 4, a series of alternative conformations of MK-2 (Figure S12D-E) were also generated from the structures most often depicted by representations in the literature and then were energy optimized. Conformations D-H in Figure S12 were generated to compare these conformations energetically to the two U-shaped conformations shown in Figure 4A-B. The energies of conformations D-H in Figure S12 were all higher $(\sim 11$ to $\sim 23 \mathrm{kcal} / \mathrm{mol})$ than the conformations found in $d_{6}$-DMSO, $d_{5}$-pyridine, and conformation C (Figure S12). Additional analysis of conformations and a table of selected internuclear distances of MK-2 conformations from Figure 4 and Figure S12 are given in Table S1.

Selected simple alkanes and a few other, more complex compounds with long alkyl-segments such as in polyenes and fatty acids report that the extended and folded forms are comparable in energy to the all-trans form. ${ }^{29,30}$ The "pentane effect" for longer chains destabilizes the gauche conformations because of unfavorable $\mathrm{g}^{+} \mathrm{g}^{-}$arrangements, which increases the energy by $\sim 0.55 \mathrm{kcal} / \mathrm{mol}$ with each kink in the chain. ${ }^{29,30}$ In contrast, gauche arrangements are often energetically favored because of entropic contributions. ${ }^{31,32}$ This is in part due to the spatial requirements that all molecules exert and can be justified using limited sphere considerations. ${ }^{33}$ Gauche arrangements tend to favor folded conformations where the degree of folding of $n$ alkanes $\left(\mathrm{C}_{5}-\mathrm{C}_{32}\right)$ in solution depends on the strength of the dispersion force of the solvent ${ }^{35}$ and the degree of folding increases with increasing chain length of the solute. ${ }^{34,36}$ Other molecules that contain alkyl chains such as fatty acids and polyethylene derivatives have also been reported as either extended chains or in folded conformations depending on physical and environmental conditions. ${ }^{31,32,37,38}$ Conformational analysis of long chain allylic polyunsaturated fatty acid chains using Hartree-Fock calculations showed that conformational differences between the all-trans and helical folded structures are only a few $\mathrm{kcal} / \mathrm{mol} .{ }^{37}$ Ultimately, there are a few but strongly convincing examples s $^{30,39-42}$ that folded and/or U-shaped conformations are likely to become much more important than have been recognized previously. The studies presented herein represent a new class of compounds that adopt a U-shaped conformation, illustrating that these folded conformations are likely to be important and may impact the biological function of these lipoquinone systems. It is very important to recognize the molecular plasticity, which allows the alkyl chain to assume shapes depending on the complementary structures or influences of the immediately surrounding environment.

Electrochemistry of MK-2 in Different Solvents. Our interest in these systems relates to the fact that the redox potential of MK is important in shuttling electrons between protein complexes. Although the focus of this manuscript has been on the conformations of these compounds, we are particularly interested in redox properties because we are aiming 
to investigate the function of these systems as well. For MKs to carry out this process, MKs must associate with the transmembrane proteins involved in the electron-transfer processes. ${ }^{49}$ The electron-transfer processes all take place within or near the membrane interface with two one electron reduction processes sequentially forming the radical anion (semiquinone) and then the dianion. ${ }^{50-52}$ Even though there has been many reports in literature on the redox potentials of MK derivatives, the origin of these changes is not well understood. ${ }^{50-52}$ These processes are particularly poorly understood when the quinones are present in a hydrophobic molecule that is entirely or partly located in the membrane of a biological system. Although, it is premature to correlate conformation with redox potential, we are seeking systematic information where redox potentials and conformations are known (i.e., within different organic solvents) and the electrochemical data on this system becomes an important frame of reference because the conformational analysis has been carried out. We hypothesized that the redox potential of MK-2 will vary based on organic solvent environment.

Although this hypothesis would be anticipated to be confirmed, it is important to measure how and if the magnitude of the redox potential changes as the solvent environment changes because the function of MK-2 is tied to the redox potentials. Initially, redox studies were planned to be carried out in DMSO, acetonitrile, and benzene; however, because of low solubility of all of the electrolytes examined in benzene, benzene was replaced with pyridine as a representative aromatic solvent. ${ }^{53}$ The electrolyte tetrabutylammonium perchlorate (TBAP) was chosen because $1 \mathrm{D}^{1} \mathrm{H}$ NMR studies showed that the addition of TBAP to MK-2 solutions (solvents: $d_{6}$-DMSO, $d_{5}$-pyridine, $d_{3}$ acetonitrile) did not affect the observed chemical shifts of the MK-2 protons, and thus no evidence for artifacts due to ion pairing would be observed (see Supporting Information for further description of the electrochemical analysis, and see Figure S13 for MK-2/TBAP NMR studies).

MK-2's first electrochemical potential is the one electron reduction of the quinone to semiquinone $\left(\mathrm{Q} / \mathrm{Q}^{\bullet-}\right)$, and the second is the one electron reduction of the semiquinone to the dianion $\left(\mathrm{Q}^{\bullet-} / \mathrm{Q}^{2-}\right)$, Scheme $\mathrm{S} 1^{50-52}$ The cyclic voltammogram's (CVs) of MK-2 and an internal standard of ferrocene $\left(\mathrm{Fc}^{+} / \mathrm{Fc}\right)$ in three organic solvents are shown in Figure 5. The $\mathrm{Q}$ $\mathrm{Q}^{\bullet-} E_{1 / 2}$ vs $\mathrm{Fc}^{+} / \mathrm{Fc}$ for MK-2 in DMSO, $\mathrm{CH}_{3} \mathrm{CN}$, and pyridine were measured to be $-1.155( \pm 0.001) \mathrm{V},-1.230( \pm 0.003) \mathrm{V}$, and $-1.331( \pm 0.001) \mathrm{V}$, respectively. As shown in Figure 5, we included the $\mathrm{Fc}^{+} / \mathrm{Fc}$ reference in the data presented. These results are consistent with $\mathrm{Q} / \mathrm{Q}^{\bullet-} E_{1 / 2} \mathrm{vs}^{\mathrm{Fc}^{+}} / \mathrm{Fc}$ values given for 1,4-naphthoquinone. ${ }^{50,54}$ The values determined experimentally for $\mathrm{Q}^{\bullet-} / \mathrm{Q}^{2-} E_{1 / 2}$ vs $\mathrm{Fc}^{+} / \mathrm{Fc}$ for MK-2 in DMSO, $\mathrm{CH}_{3} \mathrm{CN}$, and pyridine were measured to be $-1.863( \pm 0.008) \mathrm{V},-1.902$ $( \pm 0.012) \mathrm{V}$, and $-2.075( \pm 0.003) \mathrm{V}$, respectively (Table S2). In Figure 6, the half-wave potentials are plotted showing the trend that both redox processes are more readily reduced in DMSO than $\mathrm{CH}_{3} \mathrm{CN}$ or pyridine similar to the trend observed in literature for 1,4-napthoquinone potentials. ${ }^{54}$

In summary, during the first electrochemical process producing the semiquinone, MK-2 has the most positive potential in DMSO and the most negative potential in pyridine, showing MK-2 is slightly more reducible in DMSO than pyridine or $\mathrm{CH}_{3} \mathrm{CN}$. The observation of differing redox potentials between organic solvents supports the second hypothesis that the redox potential of MK-2 is influenced by the specific organic solvent, where a contributing factor to the observed changes is due to the differences between the dielectric constant of each

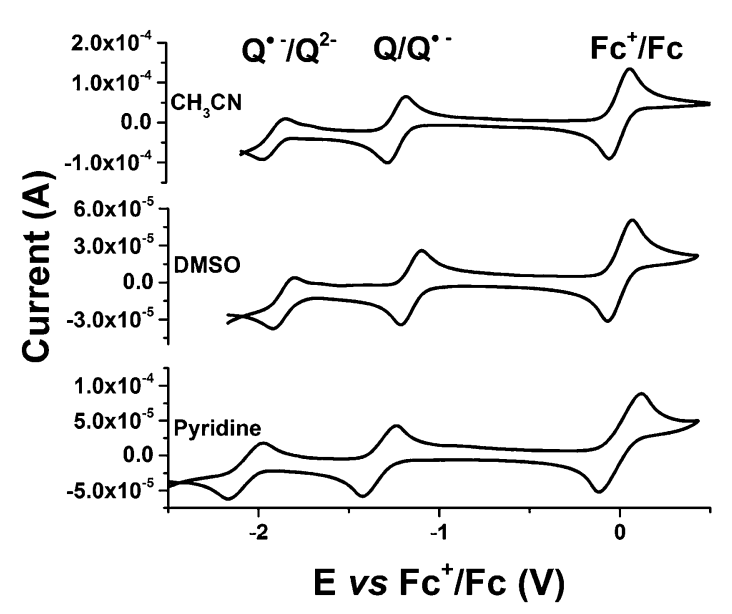

Figure 5. Three representative CVs of $2 \mathrm{mM} \mathrm{MK}-2$ in $\mathrm{CH}_{3} \mathrm{CN}$, DMSO, and pyridine. The potentials are referenced to the $\mathrm{Fc}^{+} / \mathrm{Fc}$ couple (2 $\mathrm{mM}$ ) determined in each solvent. From left to right, redox processes are $\mathrm{Q}^{\bullet-} / \mathrm{Q}^{2-}, \mathrm{Q} / \mathrm{Q}^{\bullet-}$, and $\mathrm{Fc}^{+} / \mathrm{Fc}$. Each sample has $0.1 \mathrm{M}$ TBAP and was degassed with argon gas for $10 \mathrm{~min}$ at ambient room temperature before spectra were recorded. Current sweeps are in the anodic direction from $-2 \mathrm{~V}$ to $1 \mathrm{~V}$ and back to $-2 \mathrm{~V}$. A $100 \mathrm{mV}$ scan rate was used.

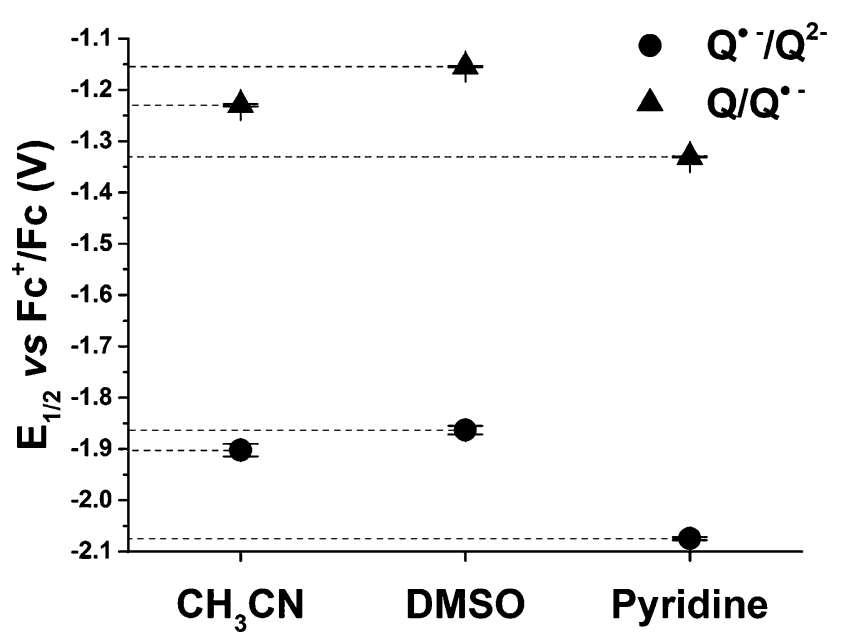

Figure 6. Measured $E_{1 / 2}\left(\mathrm{vs} \mathrm{Fc}^{+} / \mathrm{Fc}\right.$ in $\left.\mathrm{V}\right)$ of $\mathrm{MK}-2 \mathrm{Q} / \mathrm{Q}^{\bullet-}$ and $\mathrm{Q}^{\bullet-} / \mathrm{Q}^{2-}$ redox processes vs solvent. Added lines show the distinction between each solvent for each redox process. Each solvent was run in triplicate with error bars shown. Student's $t$ test indicated the half wave potentials of each redox process are significantly different in each solvent $(p<0.01$ for $\mathrm{Q}^{\bullet-} / \mathrm{Q}^{2-} \mathrm{CH}_{3} \mathrm{CN}-\mathrm{DMSO}$ and $p<0.0001$ for all other comparisons). See Supporting Information for details.

solvent. The different organic solvents influence the observed redox potential of MK-2, and from the 2D NMR studies on the conformation of MK-2, slight differences in conformation were observed, which may suggest that a combination of solvent effect and conformational differences of MK-2 may affect the redox potential.

Interaction of Langmuir Phospholipid Monolayers with MK-2. The physiologically relevant environment for MKs is in association with membranes; therefore, we also studied the interaction of MK-2 with a more direct model membrane interface, a phospholipid monolayer. Several membrane models exist including Langmuir phospholipid monolayers, liposomes, micelles, and reverse micelles (RM) (Figure 7). ${ }^{55-61}$ Each model system has advantages and disadvantages, and we have chosen to investigate the 

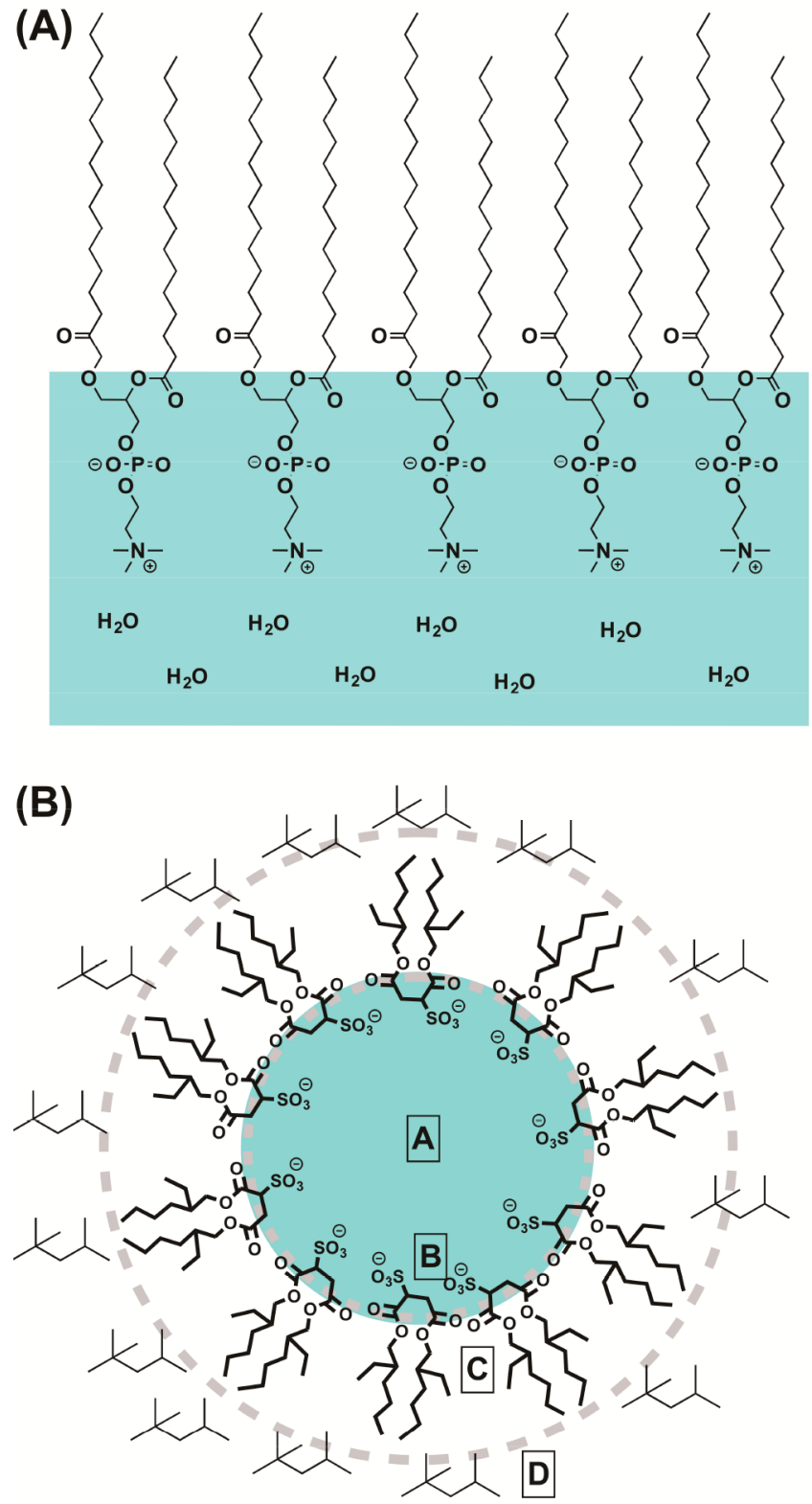

Figure 7. Schematic diagram of (A) a Langmuir phospholipid monolayer and (B) a RM present in a microemulsion. Labeling for the RM is as follows: the water pool (A), the Stern layer (B), the surfactant tails (C), and the organic solvent, isooctane (D).

phospholipid monolayer because of MKs direct association with a membrane and the RM system because RMs allow for the determination of molecular placement and conformation of MK2 within the interface. ${ }^{55-61}$

First, we describe our studies with Langmuir phospholipid monolayers ${ }^{60,61}$ consisting of phospholipids to gain insight into the interactions between two classes of phospholipids (dipalmitoylphosphatidylcholine (DPPC) or dipalmitoylphosphatidylethanolamine (DPPE)) and MK derivatives. These studies will demonstrate how the phospholipid packing is affected by the presence of MK derivatives as it interacts with the phospholipid interface (Figure $7 \mathrm{~A}$ ). ${ }^{60,62-65}$ Due to the low solubility of MK-2 in aqueous environments, the Langmuir phospholipid monolayer studies involve experimental protocols used for other materials with low solubility in water, such as UBQ. ${ }^{66,67}$ Figure 8 shows the change in surface pressure as a function of area per molecule of DPPC or DPPE in the presence of various amounts of MK-2. The resulting compression moduli as functions of surface pressure are shown in Figure S14.

The compression isotherm of DPPC shows a transition at $\sim 8$ $\mathrm{mN} / \mathrm{m}$ and both DPPC and DPPE collapse at $\sim 55 \mathrm{mN} / \mathrm{m}$ similar to findings reported in literature. ${ }^{68}$ The compression isotherm of the 1:1 mixture of DPPC and MK-2 shows a disappearance of the gas to liquid phase transition at $8 \mathrm{mN} / \mathrm{m}$, suggesting there is a condensing effect of MK-2 with DPPC at a high area per molecule/low surface pressure. Moving to DPPE, the 1:1 mixture of MK-2 with DPPE reduces the collapse pressure of the film to $50 \mathrm{mN} / \mathrm{m}$, showing destabilization of the DPPE film. The pure MK-2 films had limited stability shown by a maximum surface pressure of $\sim 20 \mathrm{mN} / \mathrm{m}$. This result suggests MK-2 forms a less stable film than the phospholipids. ${ }^{66-68}$ To understand the interactions of MK-2 with DPPE and DPPC further, the compression moduli were calculated using equation 4 (see Supporting Information), where the compression modulus is the measure of the compressibility of the film.

Our results are interpreted as MK-2 having a condensing effect on DPPC phospholipid films at high area per molecule/low pressure and destabilization of DPPE phospholipid films. The resulting mixed films (DPPC/MK-2 or DPPE/MK-2) were also consistent with reported UBQ, suggesting similar trends where UBQ was shown to be compressed out of the phospholipid interface. ${ }^{66,67,69}$ In summary, MK-2 has a condensing effect on DPPC phospholipid films, a destabilization of DPPE phospholipid films, and is most likely compressed out of the phospholipid film similar to UBQ. ${ }^{66,67,69}$ Unfortunately, these studies do not directly show whether a folded or extended conformation of MK2 exists. A folded conformation occupies a larger volume than the extended conformation, which would affect packing within the phospholipid interface. Our studies do demonstrate that MK-2 interacts with the phospholipid model membrane interfaces of DPPC and DPPE even above physiologically relevant pressures. It is possible that the observation of the destabilization of the DPPE phospholipid films (not observed for DPPC) by the presence of the MK may suggest a folded MK-2 conformation that does not fit in the organization of the DPPE film (possibly related to packing of the phospholipid).

1D ${ }^{1} \mathrm{H}$ NMR Spectroscopic Studies of MK-2 in RMs. Our ultimate objective was to characterize the molecular details of MK-2's association with membrane-like interfaces. This characterization includes determining the location and conformation of MK-2; therefore, the RM model system was investigated (Figure 7B). ${ }^{60,62-65,70}$ In the RM, a ternary microemulsion system forms when a surfactant is dissolved in an organic solvent and the addition of water creates nanosized water droplets encased in surfactant. ${ }^{56,63,65,70-72}$ This dynamic, yet simple, model can provide molecular detail on location and conformation of $\mathrm{MK}$ at an interface using NMR spectroscopy, whereas the use of phospholipids such as DPPC can have overlapping proton signals with key $\mathrm{MK}$ proton signals making interpreting conformational information very complex. ${ }^{70,73-76}$ RM systems provide information regarding the location, conformation, and physical interactions of MK with lipid films and potentially membranes, which allowed us to examine our third hypothesis that the membrane interface influences the conformation of the MK derivative.

To explore the location of MK-2 at a lipid/water interface further, studies were conducted using a simple microemulsion interfacial system, which allows for identification of molecular placement. Figure 9 shows a stack plot of $1 \mathrm{D}^{1} \mathrm{H}$ NMR spectra for 
(A)

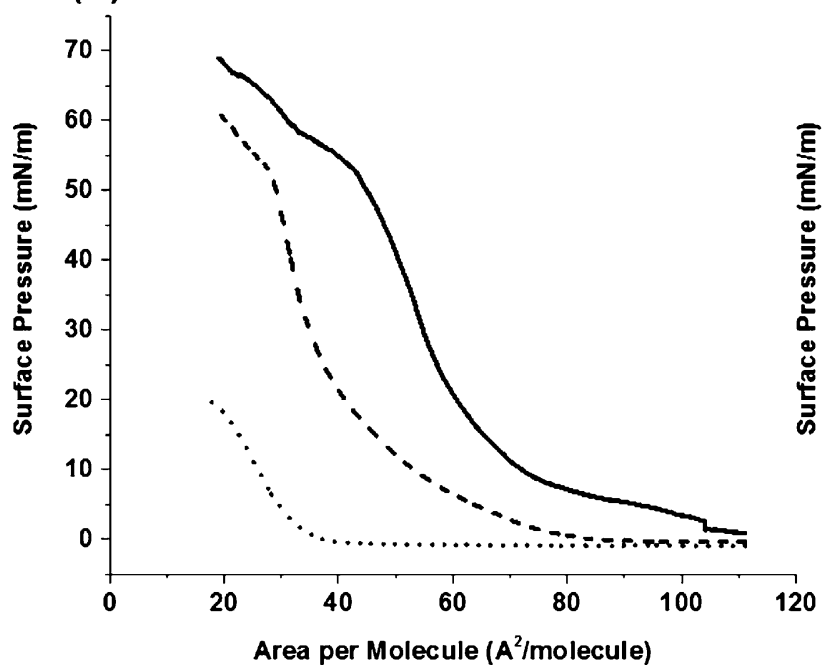

(B)

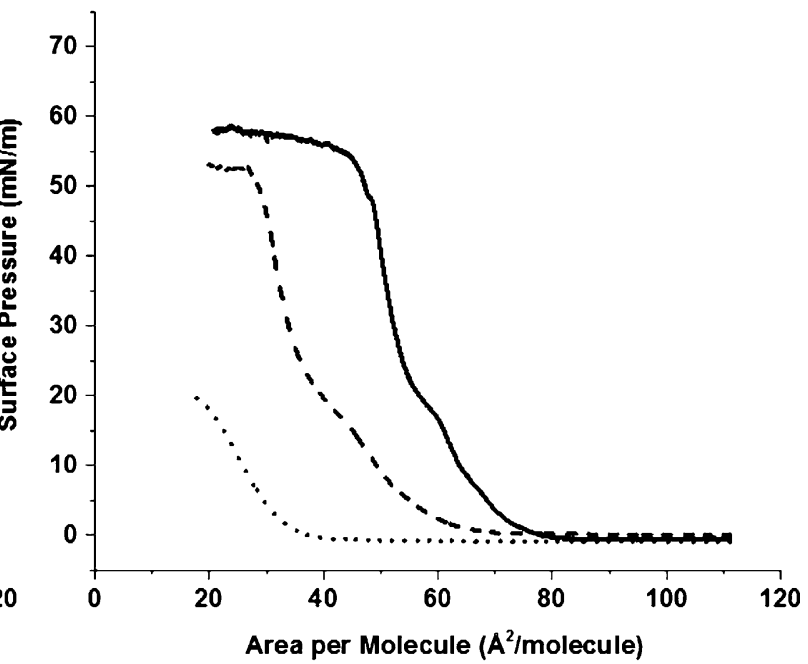

Figure 8. Compression isotherms of MK-2 films (dotted lines), DPPC or DPPE phospholipid films (solid lines), or a 50:50 mixture of MK-2 and phospholipid (dashed line). On the left (A) are the resulting compression isotherms of MK-2 and DPPC, while on the right (B) are the resulting compression isotherms of MK-2 and DPPE.

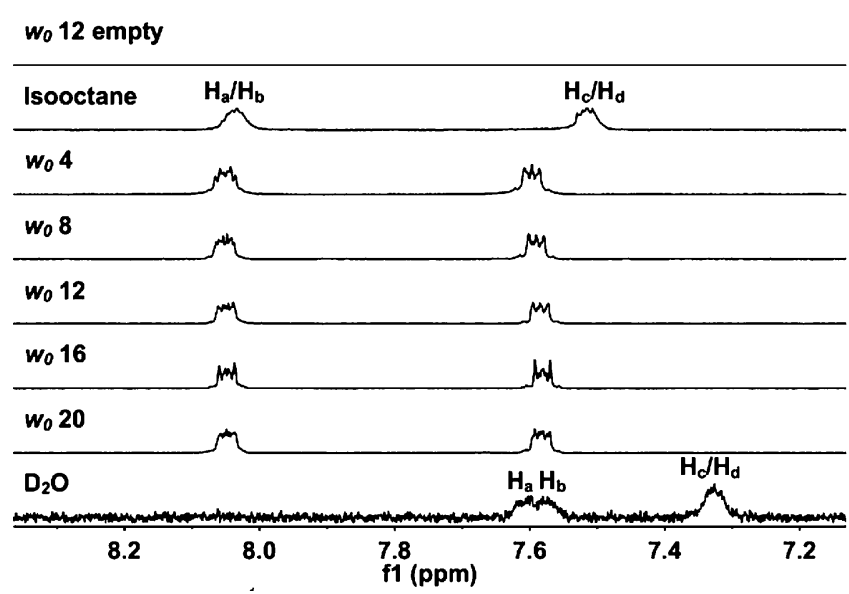

Figure 9. $1 \mathrm{D}{ }^{1} \mathrm{H}$ NMR $(400 \mathrm{MHz})$ spectra of MK-2's aromatic protons, $\mathrm{H}_{a}, \mathrm{H}_{\mathrm{b}}, \mathrm{H}_{c}$, and $\mathrm{H}_{\mathrm{d}}$ in $\mathrm{D}_{2} \mathrm{O}$, isooctane, and different sized RMs. Proton peak text labeling corresponds to MK-2 proton labeling scheme key found in Figure 3. $\mathrm{H}_{a}, \mathrm{H}_{\mathrm{b}}, \mathrm{H}_{\mathcal{c}}$ and $\mathrm{H}_{\mathrm{d}}$ protons undergo a chemical shift upon inclusion inside RMs.

the aromatic protons $\left(\mathrm{H}_{\mathrm{a}} / \mathrm{H}_{\mathrm{b}}\right.$ and $\left.\mathrm{H}_{\mathrm{c}} / \mathrm{H}_{\mathrm{d}}\right)$ of MK-2 in solutions of $\mathrm{D}_{2} \mathrm{O}$, isooctane, or isooctane solutions of $\mathrm{MK}-2$ containing $\mathrm{RMs}\left(\mathrm{D}_{2} \mathrm{O} / \mathrm{AOT} /\right.$ isooctane microemulsions) of various sizes $\left(w_{0}: 4,8,12,16\right.$, and 20 , where $\left.w_{0}=\left[\mathrm{D}_{2} \mathrm{O}\right] /[\mathrm{AOT}]\right)$ and for comparison with an empty AOT/isooctane RM. The aromatic MK-2 protons in the AOT/isooctane RMs are similar to the signals observed in isooctane but very different from the signals observed in $\mathrm{D}_{2} \mathrm{O}$. The distance between $\mathrm{H}_{\mathrm{a}} / \mathrm{H}_{\mathrm{b}}$ and $\mathrm{H}_{\mathrm{c}} / \mathrm{H}_{\mathrm{d}}$ is $0.52 \mathrm{ppm}$ in isooctane, $0.47 \mathrm{ppm}$ in the $\mathrm{RM}$, and $0.27 \mathrm{ppm}$ in $\mathrm{D}_{2} \mathrm{O}$. This suggests that the environment of the MK- 2 protons in the AOT/isooctane $\mathrm{RMs}$ is more like an environment in isooctane than $\mathrm{D}_{2} \mathrm{O}$, where $\mathrm{MK}-2$ is no longer in isooctane but associating with the AOT molecules. The signals from the $\mathrm{H}_{\mathrm{c}} / \mathrm{H}_{\mathrm{d}}$ protons in the AOT/isooctane RMs do change slightly as the RM size increase or decreases. This observation is also consistent with MK-2 penetrating and residing in the interface.

To verify that the RMs formed in the samples used and that the properties of the samples are consistent with previous studies, ${ }^{61,63,70,77,78}$ dynamic light scattering (DLS) experiments were carried out. These studies confirmed the formation of RMs, and that the RM did not change significantly upon the addition of MK-2. This was carried out by measuring the sizes in the presence and absence of MK-2 and confirming that the size was as those reported previously (data not shown). ${ }^{63}$ Overall, these results are consistent with MK-2 penetrating the RM model membrane interface; however, $2 \mathrm{D}$ studies are described below to get more information regarding the placement and conformation of MK-2 within the RM system.

${ }^{1} \mathrm{H}-{ }^{1} \mathrm{H}$ 2D NOESY and ROESY NMR Spectroscopic Studies of MK-2 in a RM Model Membrane System. To provide further evidence regarding the location, orientation, and conformation of MK-2 within RMs, we obtained the ${ }^{1} \mathrm{H}-{ }^{1} \mathrm{H} 2 \mathrm{D}$ NOESY NMR spectrum and the ${ }^{1} \mathrm{H}-{ }^{1} \mathrm{H} 2 \mathrm{D}$ ROESY NMR spectrum of MK-2 in a $w_{0} 12 \mathrm{RM}$, Figures 10 and 11 . Figure 10 shows a partial ${ }^{1} \mathrm{H}-{ }^{1} \mathrm{H} 2 \mathrm{D}$ NOESY and ROESY NMR spectra indicating both AOT and MK-2 protons, whereas Figure 11 focused in on selected proton interactions specifically in the NOESY spectrum (see Figures S10-S11 for full spectra). Figure $11 \mathrm{~A}$ shows cross peaks between the aromatic $\mathrm{H}_{\mathrm{a}} / \mathrm{H}_{\mathrm{b}}$ and $\mathrm{H}_{\mathrm{c}} / \mathrm{H}_{\mathrm{d}}$ and parts of the AOT $\mathrm{CH}_{2}$ and $\mathrm{CH}_{3}$ tail groups (i.e., $\mathrm{H}^{\prime}$ and $\mathrm{H} 10^{\prime}$ protons, see Figure 12 for AOT proton labeling key). Figure 11B shows cross peaks between alkene protons, $\mathrm{H}_{\mathrm{i}}$ and $\mathrm{H}_{\mathrm{h}}$, with HOD and AOT's $\mathrm{H} 1, \mathrm{H} 1^{\prime}, \mathrm{H} 3$, and $\mathrm{H}^{\prime}$ ' protons and only evidence of a weak interaction between MK-2 and isooctane. These interactions are consistent with placement of MK-2 between the AOT tails, as shown using a depth perception drawing in Figure 12.

Regarding the conformation of MK-2 associated with the $\mathrm{RM}$-water interface, the NOE and ROE cross peaks in Figure 10 show interactions between $\mathrm{H}_{w}$ and $\mathrm{H}_{\mathrm{z}} / \mathrm{H}_{\mathrm{y}}$ and between $\mathrm{H}_{\mathrm{w}}$ and the alkene protons, $\mathrm{H}_{h} / \mathrm{H}_{\mathrm{i}}$, which is consistent with a folded, $\mathrm{U}$ shaped conformation. In the proposed conformation, the C2C6 atom to atom distance in MK-2's isoprenyl side-chain was found to be $3.6 \AA$, which is consistent with a U-shape $\left(\mathrm{g}^{+} \mathrm{g}^{-}\right.$ conformation, Figure 13) for MK-2 placed at the RM interface (see Supporting Information for further discussion and internuclear distances of different MK-2 conformations). An illustration of an MK-2 conformation consistent with these observations is shown in Figure 13. This U-shaped conformation 


\section{(A) Partial NOESY RM}

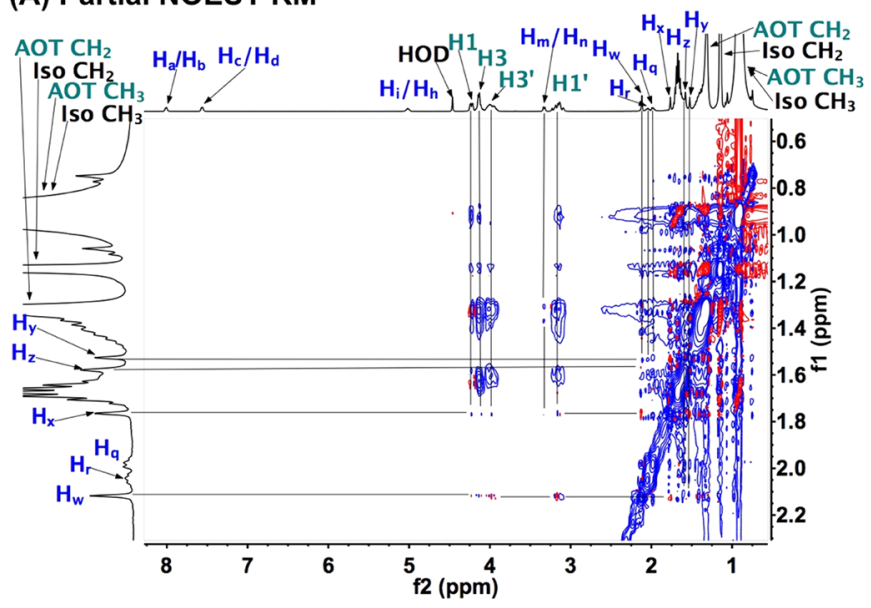

(B) Partial ROESY RM

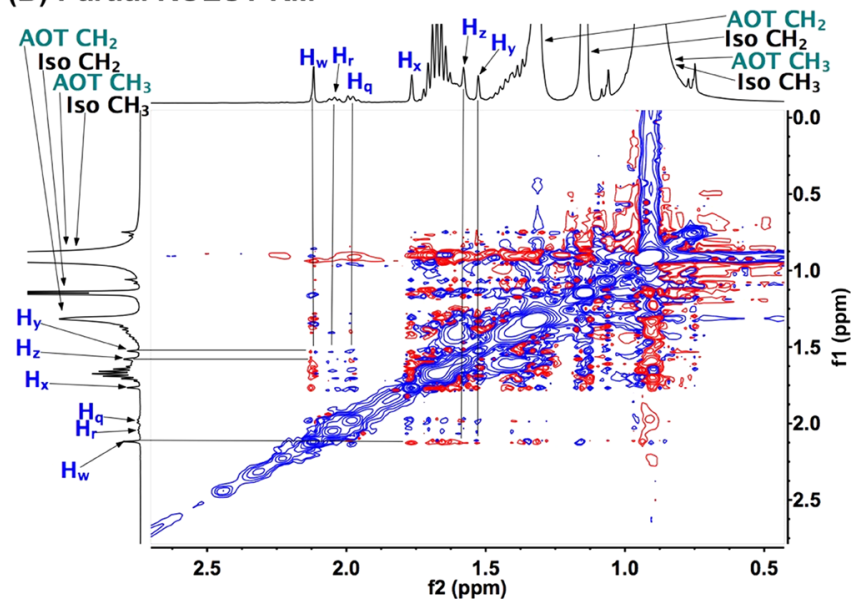

Figure 10. Partial ${ }^{1} \mathrm{H}-{ }^{1} \mathrm{H} 2 \mathrm{D}$ NOESY and ROESY NMR ( $400 \mathrm{MHz}$ ) spectra of MK-2 inside $w_{0} 12 \mathrm{RM}$ at $26{ }^{\circ} \mathrm{C}$. (A) Partial ${ }^{1} \mathrm{H}-{ }^{1} \mathrm{H} 2 \mathrm{D}$ NOESY NMR spectrum in a $w_{0} 12 \mathrm{RM}$. (B) Partial ${ }^{1} \mathrm{H}-{ }^{1} \mathrm{H}$ 2D ROESY NMR spectrum in a $w_{0} 12 \mathrm{RM}$. Blue to blue proton text labeling shows MK-2 to MK-2 interactions, teal to teal proton text labeling shows AOT to AOT interactions, and blue to teal proton text labeling shows MK-2 to AOT interactions. Blue intensity contours represent negative NOE's or ROE's and red intensity contours represent positive NOE's or ROE's. A standard NOESY pulse sequence was used consisting of 256 transients with 16 scans in the f1 domain using a $200 \mathrm{~ms}$ mixing time and a $1.5 \mathrm{~s}$ relaxation delay. A standard ROESYAD pulse sequence was used consisting of 256 transients with 16 scans in the f1 domain using a 200 ms mixing time and a $2.0 \mathrm{~s}$ relaxation delay. See Figure 3 for MK-2 proton labeling scheme key and Figure 12 for AOT proton labeling scheme key.
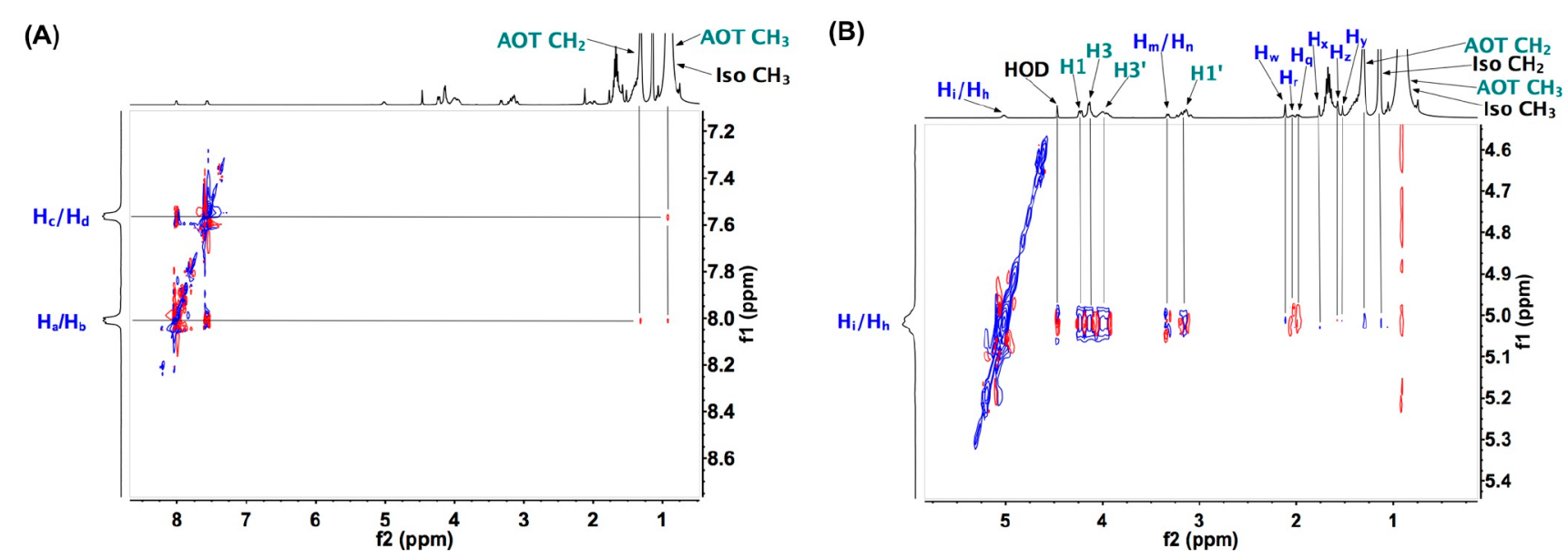

Figure 11. Partial ${ }^{1} \mathrm{H}-{ }^{1} \mathrm{H} 2 \mathrm{D}$ NOESY NMR (400 MHz) spectra of MK-2 inside a $w_{0} 12 \mathrm{RM}$ at $26{ }^{\circ} \mathrm{C}$ illustrating interactions of MK-2 with the AOT surfactant tails. (A) Interactions between MK-2's aromatic protons and AOT. (B) Interactions between MK-2 alkene protons and AOT. The blue to blue proton text labeling shows MK-2 to MK-2 interactions, teal to teal proton text labeling shows AOT to AOT interactions, and blue to teal proton text labeling shows MK-2 to AOT interactions. Blue intensity contours represent negative NOE's, and red intensity contours represent positive NOE's. A standard NOESY pulse sequence was used consisting of 256 transients with $16 \mathrm{scans}$ in the f1 domain using a $200 \mathrm{~ms}$ mixing time and a $1.5 \mathrm{~s}$ relaxation delay. See Figure 3 for MK-2 proton labeling scheme key and Figure 12 for AOT proton labeling scheme key.

observed when MK-2 is associated within the RMs changed slightly from that observed in $d_{6}$-DMSO regarding where the double bond overlaps with the napthoquinone moiety. The overlap of the alkene and napthoquinone functionalities in the conformation associated with the interface is best illustrated by the top view in Figure 13B. Importantly, the U-shape fold remains, but slight rotation around the $\mathrm{C}-\mathrm{C}$ bond facilitates the conformational changes in the U-shape.

Implications of Folded Conformations for MK Derivatives. Natural MKs contain a naphthoquinone and an isoprenyl side-chain with some variable number of repeating isoprene units, where MKs support the electron-transfer reactions in a range of systems. ${ }^{6,43}$ MK-2 was synthesized allowing for detailed characterization of the molecule. The results presented herein for MK-2 suggests that other important MK derivatives in biology will adopt folded conformations as well and demonstrates the need to prepare and study such derivatives both experimentally and computationally.

The extended conformations of long chain biological molecules such as fatty acids and polyenes are generally shown in the literature if the structure is presented. ${ }^{7,23,24}$ However, a few studies of isoprene conformers and 1,3 acyclic dienes show the extended trans alkane conformations compare in energy with folded or helical conformations. ${ }^{790}$ Although the folded conformations in those studies may be slightly higher in energy than unfolded conformations, the difference is surprisingly small. The $\mathrm{C}-\mathrm{C}$ single bond lengths reported for stearic acid decreases under high pressure. ${ }^{42}$ These bond shrinkages cause conformational and shape changes in stearic acid favoring folded conformations. $^{42}$ Previous studies using high-temperature UVabsorption spectroscopy, molecular orbital calculations, and gasphase electron diffraction found that isoprene and chloroprene 


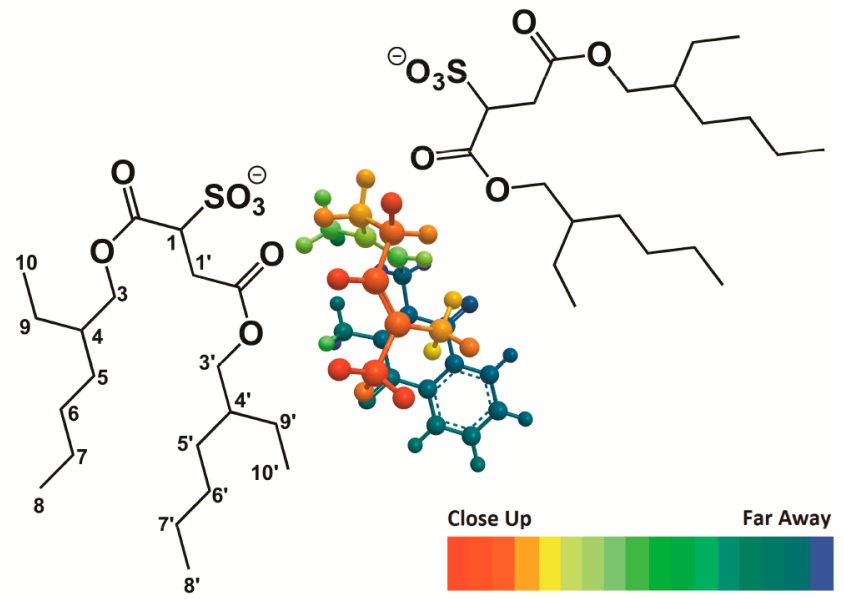

Figure 12. Illustration of MK-2's proposed folded, U-shaped conformation and placement in the RM interface. This arrangement is consistent with ${ }^{1} \mathrm{H}-{ }^{1} \mathrm{H} 2 \mathrm{D}$ NOESY and ROESY NMR spectral data obtained in a $w_{0} 12 \mathrm{RM}$; however, MK-2 likely tumbles freely within the interface but maintains interactions with the region of AOT shown in the illustration. Color depth fading legend shows dark red as closer in distance and dark blue as farther in distance from the reader. AOT proton labeling scheme key is shown.
(A)

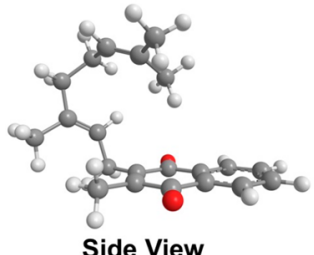

(B)

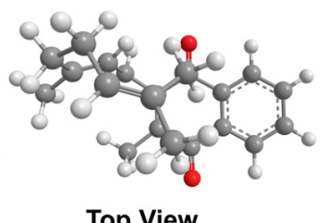

Figure 13. MK-2 conformation at an interface visualized using MMFF94 calculations. Molecular mechanics simulations generating the $3 \mathrm{D}$ conformation of MK-2 in a RM that is consistent with ${ }^{1} \mathrm{H}-{ }^{1} \mathrm{H}$ 2D NOESY and ROESY NMR spectral data. (A) Side view of energy minimized conformation $\left(63.5 \mathrm{kcal} / \mathrm{mol}\right.$, and internuclear distance $\mathrm{H}_{\mathrm{w}}-$ $\mathrm{H}_{\mathrm{z}}: 4.0 \AA$ A) showing MK-2's isoprene side-chain adopting a hook-like shape also known as a folded, U-shaped conformation. (B) Top view of energy minimized conformation showing the terminal isoprene methyl groups overlapping the carbonyl groups on the napthoquinone.

conformations did, in fact, favor folded conformations. ${ }^{81,82}$ Although these conditions are nonphysiological, they do demonstrate that changes in a physical parameter can affect the preferred conformation. Previous work has been carried out with fatty acids where the experimental studies showed that the conformations of the alkane portion of the fatty acids can and do change similar to conformations of MK-2 as shown in this work. ${ }^{37}$ Our studies confirm the first hypothesis that MKs have different conformations depending on specific environmental conditions, which was achieved by first synthesizing MK-2 and then demonstrating that a U-shaped, folded conformation was adopted in $d_{6}$-DMSO, which was different from the conformation in $d_{5}$-pyridine.

Conformations can affect reactivity, and as in this case, the electron-transfer reactions facilitated by MK. MK forms complexes with several enzymes during the electron-transfer processes, and although kinetic characterizations of these systems have been reported, ${ }^{83-85}$ less is known structurally. The redox potentials of MK-2 depicted in Figure 6 illustrate the trend where the most positive potential is in DMSO and the most negative potential is in pyridine, which agrees with literature reports on menadione. ${ }^{50,54}$ These results have identified that the redox potential of MK-2 changes as a function of solvent, and the origin of this change (presumably in part due to a change in dielectric constant between solvents) and whether these observed solvent effects can be associated with changes in conformation should be investigated in the future using both suitable high-level computational methods as well as electrochemistry. Indeed, the change in redox potential is likely to be important, and since there is no conjugation between the isoprenyl side-chain and napthoquinone, these effects are very interesting and may reflect that the energy required for the reduction is determined by the energy difference of the HOMO-LUMO gap in the two different conformations. ${ }^{86}$ Orbital analysis of the HOMO-LUMO gap could potentially be informative and describe the origin of the observed varied biological effects of a series of $N$-alkyl MK derivatives that have been reported. ${ }^{87,88}$ For example, replacement of a $\mathrm{CH}_{2}$ group with a $\mathrm{N}$ atom modifies the parent system, creating a class of compounds with a nitrogen bound directly to the "naphthoquinone group." These molecules have dramatically different biological properties than the parent MK derivatives, ${ }^{87,88}$ and it is possible that these activities could be related to the change in fundamental physical and chemical properties that occurs with $\mathrm{N}$-alkyl isoprenoid substitution of the naphthoquinone ring. Combined, these results confirm the second hypothesis that the redox potential of MK-2 is influenced by organic solvent environment (in part due to dielectric constant of solvent), which is likely to be important for understanding the mechanistic details in MK metabolism.

The third hypothesis involves determining if the association of MK with the membrane interface influences the conformation of the MK derivative. We investigated the interaction of MK-2 with a phospholipid Langmuir monolayer, which is a simple 2D model of a single leaflet of a cell membrane. ${ }^{59,89,90}$ The fact that MK-2 interacts with the phospholipid monolayer is consistent with the expected MK affinity for the hydrophobic phospholipids that make up the cell membrane. Langmuir monolayer studies support interaction of MK-2 with the phospholipid monolayer interface; however, the lipoquinone is likely compressed out of the interfacial portion of the phospholipid monolayer into the more hydrophobic alkyl tail groups on the top of the monolayer as the pressure increases. Unfortunately, Langmuir phospholipid monolayer studies could not determine the conformation of MK2; however, the RM surfactant interface complements studies with the phospholipid monolayer interface. The question of folding was further investigated by combining ${ }^{1} \mathrm{H}$ NMR spectroscopic studies of MK-2 in organic solution and in a simple model membrane system, RMs. The conformation of MK-2 was characterized in organic solvents and was found to differ slightly from the conformation when it was associated with the surfactant interface within RMs. It is to be expected that MK2 would have an affinity for the interface because of its hydrophobicity, which agrees with results observed in the RM system. The RM interface is known to be penetrated by water molecules and thus less packed than a biological membrane and, therefore, has a lower interface pressure meaning MK-2 is unlikely to be compressed out once inside. ${ }^{63,70,91}$ The ${ }^{1} \mathrm{H}$ NMR spectroscopic studies in RMs allowed us to observe the association of MK-2 with the interface molecules as well as with itself in its folded state. The ${ }^{1} \mathrm{H}-{ }^{1} \mathrm{H}$ 2D NOESY and ROESY NMR spectral data indicate that the U-shaped conformation of MK-2 (Figure 13) remained intact while 
associating with the RM model membrane interface; however, the overlap between the alkene and the napthoquinone varies with the specific environment. The small changes in the Ushaped conformation document the environmental influence on the conformational folding of MK-2. These results are very important because they document the possibility that MK derivatives in the cell membrane environment may be folded, and if so, such folds will impact the interaction with proteins in the ETS and affect reactivity and function.

Naturally occurring lipoquinones are characterized by the presence of an isoprenyl side-chain of varying length depending on the species of origin. MK-2's isoprenyl side-chain is shorter than most lipoquinones involved in electron transport; therefore, it may not fully mimic the interactions generated by MK derivatives with longer isoprene chains with the membrane or the enzyme systems. However, these results show that the folding of MK-2 is very important and may suggest that MK derivatives with the longer isoprenyl side-chains may adopt folded conformations as well. Understanding how MK-2 and other MK derivatives fold in a hydrophobic environment is critical to gauge how these molecules will behave within a biological membrane associated with the ETS.

Investigation of the conformation of a particular $\mathrm{MK}$ derivative's location and conformation will also allow for a more realistic interpretation of data obtained with the novel fluorogenic probe, a vitamin $\mathrm{K}$ analog, reported to fluoresce after reduction to the quinol. ${ }^{92}$ Studies with this new probe may help provide information on the role that vitamin K plays in key redox processes. Accurate information obtained from the use of this probe would provide better quality data regarding photosynthesis and cellular respiration, and future consideration of $\mathrm{MK}$ derivatives location and conformation will be important for proper interpretation of the results obtained from the use of this probe. $^{92}$

\section{CONCLUSIONS}

Conformations exhibited by alkanes and alkenes are essential for explaining trends in reactivity and manifestation of physical properties, but little is understood regarding biological systems with hydrophobic small components containing alkyl segments. The studies presented in this manuscript describe the chemical and biochemical properties of $\mathrm{MK}$, which is an essential component of the ETS in many Gram-positive bacteria, including pathogens such as Mycobacterium tuberculosis, Mycobacterium leprae, and Staphylococcus aureus, to name a few. We report for the first time in this class of molecules that MK-2 adopts a folded, U-shaped conformation in organic solution. The specific nature of the conformation varied within different organic solvents and thus confirmed our first hypothesis that MK-2 conformations are very sensitive to their environment. These findings contrast with the simple, extended conformation represented in textbooks and the literature that is shown for MK derivatives as well as the more common " $\mathrm{Q}$ ", belonging to the UBQ family of lipoquinones.

The change in the observed redox potentials of MK-2 with different organic solvents confirmed our second hypothesis. This is important for future studies probing the function of the substrate and potential correlation between conformation and redox potential of $\mathrm{MK}$ derivatives, and although most of the studies in this manuscript are of a structural nature, it is important to recognize that the function is likely related to the conformation of the MK-derivative. The discovery that MK-2 adopts a folded conformation may suggest that other MK derivatives will have similar conformations, which ultimately will impact all the biological systems in which MKs have a role such as within the ETS in specific Gram-positive bacterial pathogens. The result of a stable U-shape conformation in solution and within an interface is important as little information is available on essential hydrophobic biological components.

Although the NMR spectral data illustrated using molecular mechanics allowed for the conclusion that MK-2's conformation is environment dependent, it was important to investigate if this U-shaped conformation remained at a membrane-like interface. We used two membrane model systems to investigate this question. The more physiologically relevant DPPC/DPPE phospholipid monolayers confirmed that MK-2 interacted with the phospholipid interface similar to UBQs; however, the conformation of MK-2 remained unspecified. Complementary studies using the AOT-RM model membrane system allowed determination of the molecular location of MK-2 as penetrating the water-surfactant interface as well as the conformation of MK-2 within the RM interface. We found that the folded, Ushaped conformations observed in organic solution remained upon association with the AOT-RM interface, but the U-shaped conformation differed slightly indicating the interface's environmental influence on conformation. Together, these results support the interpretation that the MKs conformation remains folded in a U-shape even in contact with a model membrane interface, which agrees with our third hypothesis.

More broadly, the results of this study will also enhance our understanding of folded conformations for chemically and biologically important hydrophobic small molecules in solutions and confined hydrophobic environments. The shape and, thus, the conformation of these molecules are relevant for molecular recognition motifs and the processing of these molecules within the membrane. This manuscript represents the first attempt to characterize the conformation as well as the chemical and biochemical properties manifested by the conformation of any electron transferring lipoquinone derivative. Although many studies have been carried out with these systems kinetically, the conformation and how this impacts the biological chemistry has not yet been addressed.

\section{EXPERIMENTAL SECTION}

Preparation of (E)-2-(3,7-Dimethylocta-2,6-dien-1-yl)-3methylnaphthalene-1,4-dione (4). To a $500 \mathrm{~mL}$ round-bottom Schlenk flask were added a stir bar, diethyl ether $(100 \mathrm{~mL})$, and menadione ( $5.00 \mathrm{~g}, 29.0 \mathrm{mmol})$. Then, $10 \%$ aq. $\mathrm{Na}_{2} \mathrm{~S}_{2} \mathrm{O}_{4}(100 \mathrm{~mL}, 57.4$ $\mathrm{mmol}$ ) was added, and the solution immediately turned dark red. After 30 min of stirring at ambient temperature, the solution was clear yellow. The aqueous layer was separated and extracted with diethyl ether $(3 \times$, $100 \mathrm{~mL}$ ). The combined organic extracts were washed with sat. $\mathrm{NaHCO}_{3}(100 \mathrm{~mL})$, followed by DDI $\mathrm{H}_{2} \mathrm{O}(100 \mathrm{~mL})$, and last with brine $(100 \mathrm{~mL})$. The combined organic extracts were dried with anhydrous $\mathrm{Na}_{2} \mathrm{SO}_{4}$ and then concentrated under reduced pressure at room temperature. The crude powder was triturated with pentane (50 $\mathrm{mL})$, vacuum filtered, and washed with pentane $(100 \mathrm{~mL})$ to yield $4.25 \mathrm{~g}$ as a pale purple solid. Menadiol formation is indicative by ${ }^{1} \mathrm{H}$ NMR $\left(\mathrm{CDCl}_{3}\right)$ by the presence of a peak at $6.64 \mathrm{ppm}$ and is consistent with literature. ${ }^{93}$

To a $100 \mathrm{~mL}$ round-bottom Schlenk flask was added ethyl acetate (16 $\mathrm{mL})$ and 1,4-dioxane $(16 \mathrm{~mL})$, which was purged/evacuated with argon repeatedly. Then, crude menadiol (2.50 g, 4:1 menadiol:menadione by NMR integration, $11.5 \mathrm{mmol}$ ) was added, followed by geraniol $(1.92 \mathrm{~g}$, $12.5 \mathrm{mmol})$, and then dropwise addition of fresh $\mathrm{BF}_{3}$ etherate $(0.8 \mathrm{~mL})$. The solution was allowed to reflux at $70-72{ }^{\circ} \mathrm{C}$ for $3 \mathrm{~h}$ under argon. The dark orange colored reaction mixture was quenched with ice- $\mathrm{H}_{2} \mathrm{O}(100$ $\mathrm{mL})$ and then extracted with diethyl ether $(3 \times, 100 \mathrm{~mL})$. The yellow 
organic extracts were washed with sat. $\mathrm{NaHCO}_{3}(100 \mathrm{~mL})$, washed with DDI $\mathrm{H}_{2} \mathrm{O}(100 \mathrm{~mL})$, washed with brine $(100 \mathrm{~mL})$, dried with anhydrous $\mathrm{Na}_{2} \mathrm{SO}_{4}$, and then concentrated under reduced pressure at room temperature to yield $3.71 \mathrm{~g}$ of crude red oil. The crude oil was purified by flash column chromatography $\left(1000 \mathrm{~mL}\right.$ of $230-400$ mesh $\mathrm{SiO}_{2}, 70 \mathrm{~mm}$ column, 20:1 pentane/ethyl acetate). The yellow oil obtained was dried under reduced pressure ( $\sim 125 \mathrm{mTorr})$ overnight to yield $0.713 \mathrm{~g}(2.31$ $\mathrm{mmol}, 20.1 \%$ yield) as a yellow solid. The scale of this reaction was $\sim 14$ times larger than the previously reported synthesis. ${ }^{45}{ }^{1} \mathrm{H}$ NMR (400 $\mathrm{MHz}, d_{6}$-DMSO) $\delta: 7.96-8.01(\mathrm{~m}, 2 \mathrm{H}), 7.80-7.84(\mathrm{~m}, 2 \mathrm{H}), 4.96-5.00$ $(\mathrm{m}, 2 \mathrm{H}), 3.30(\mathrm{~d}, 2 \mathrm{H}, J=4 \mathrm{~Hz}), 2.10(\mathrm{~s}, 3 \mathrm{H}), 1.92-2.04(\mathrm{~m}, 4 \mathrm{H}), 1.73$ $(\mathrm{s}, 3 \mathrm{H}), 1.53(\mathrm{~s}, 3 \mathrm{H}), 1.49(\mathrm{~s}, 3 \mathrm{H}) .{ }^{13} \mathrm{C}$ NMR $\left(100 \mathrm{MHz}, d_{6}\right.$-DMSO) $\delta$ : 184.7, 183.6, 145.3, 142.9, 136.4, 133.9, 131.5, 130.7, 125.9, 125.8, 123.9, 119.4, 26.0, 25.4, 25.4, 17.5, 16.1, 12.4. LRMS (ESI $70 \mathrm{eV}$, EtOAc) $\mathrm{m} / z$ : $\left[(\mathrm{M}+\mathrm{H})^{+}\right]$Calcd for $\mathrm{C}_{21} \mathrm{H}_{25} \mathrm{O}_{2}$ 309.2; found 309.2. HRMS (ESI, OTOF) $\mathrm{m} / \mathrm{z}$ : $\left[(\mathrm{M}+\mathrm{H})^{+}\right]$Calcd for $\mathrm{C}_{21} \mathrm{H}_{25} \mathrm{O}_{2}$ 309.1849; found 309.1851.

Mass Spectrometry. Low-resolution mass spectrometry (LRMS) experiments were conducted by electron spray ionization mass spectrometry (ESI) on an Agilent technologies 6130 Quadrupole LCMS. High-resolution mass spectrometry (HRMS) experiments were carried out using an Agilent 6220 TOF LC/MS ("OTOF") interfaced to an Agilent 1200 HPLC with electrospray (ESI) mode.

NMR Spectroscopic Studies. 1D and 2D ${ }^{1} \mathrm{H}$ studies were carried out both in organic solvents and more complex media (see below for $\mathrm{RM}$ studies). ${ }^{1} \mathrm{H}$ and ${ }^{13} \mathrm{C}$ spectra were recorded using a Varian Model MR400 or Model Inova 400 operating at 400 and $100 \mathrm{MHz}$, respectively. Chemical shift values $(\delta)$ are reported in ppm and referenced against the internal solvent peaks in ${ }^{1} \mathrm{H}$ NMR $\left(d_{6}\right.$-DMSO, $\delta$ at $2.50 \mathrm{ppm} ; \mathrm{CDCl}_{3}, \delta$ at $7.26 \mathrm{ppm}$; $d_{5}$-pyridine, $\delta$ at $8.74 \mathrm{ppm} ; d_{3}$-acetonitrile, $\delta$ at $1.94 \mathrm{ppm}$; $\mathrm{D}_{2} \mathrm{O}, \delta$ at $4.79 \mathrm{ppm} ; \mathrm{C}_{6} \mathrm{D}_{6}, \delta$ at $\left.7.16 \mathrm{ppm}\right)$ and in ${ }^{13} \mathrm{C}$ NMR $\left(d_{6}\right.$-DMSO, $\delta$ at $39.52 \mathrm{ppm})$. All NMR spectra were recorded at either 22 or $26^{\circ} \mathrm{C}$.

Solution 1D ${ }^{1} \mathrm{H}$ NMR Spectroscopic Studies. Samples were prepared by dissolving $\sim 5 \mathrm{mg}$ of MK-2 in either $0.5 \mathrm{~mL}$ of isooctane, $d_{5^{-}}$ pyridine, $\mathrm{C}_{6} \mathrm{D}_{6}, d_{3}$-acetonitirle, $d_{6}$-DMSO, or $\mathrm{D}_{2} \mathrm{O}$. The MK-2 sample in $\mathrm{D}_{2} \mathrm{O}$ was vortexed for $\sim 1 \mathrm{~h}$ to dissolve maximum amount of MK-2. The NMR spectrum was collected by running 32 scans and was locked onto the deuterated solvent except for isooctane, which was ran unlocked using $\mathrm{CDCl}_{3}$ as a spectral window reference.

Sample Preparation for Solution ${ }^{1} \mathrm{H}-{ }^{1} \mathrm{H}$ 2D NOESY and ROESY NMR Spectroscopic Studies. To prepare the samples in $d_{6^{-}}$ DMSO and $d_{5}$-pyridine, $0.0031 \mathrm{~g}$ of MK-2 was dissolved in $0.5 \mathrm{~mL}$ of solvent to yield a $20 \mathrm{mM}$ solution of MK-2. The NMR tubes containing the MK-2 solution were purged with argon prior to data collection.

${ }^{1} \mathrm{H}-{ }^{1} \mathrm{H}$ 2D NOESY and ROESY NMR Spectroscopy in Organic Solution. 2D NMR spectroscopic studies in organic solution were carried out on a Varian model MR400 $400 \mathrm{MHz}$ magnet at $26^{\circ} \mathrm{C}$. A standard NOESY pulse sequence was used consisting of either 200 or 256 transients with 16 scans in the f1 domain using a $500 \mathrm{~ms}$ mixing time, $45^{\circ}$ pulse angle, and a $1.5 \mathrm{~s}$ relaxation delay. A standard ROESYAD pulse sequence was used consisting of either 200 or 256 transients with 16 scans in the f1 domain using a $400 \mathrm{~ms}$ mixing time, $45^{\circ}$ pulse angle, and a $2.0 \mathrm{~s}$ relaxation delay. The NMR was locked onto either $d_{6}$-DMSO or $d_{5}$-pyridine and referenced to the internal solvent peak. The resulting spectrum was processed using MestReNova NMR software version 10.0.1.

Molecular Mechanics Calculations. To obtain visual aids of MK-2 conformations, Merck molecular force field 94 (MMFF94) molecular mechanics gas-phase simulations were conducted using ChemBio3D Ultra 12.0 at $25{ }^{\circ} \mathrm{C}$. Starting conformations were obtained from ChemDraw structures or by rotating desired bonds and then either had simulations run or simply an energy minimized to achieve the desired conformation. Conformations A-B in Figure 4 were generated and then energy minimized with a root-mean-square (RMS) gradient of 0.1 and up to 50 iterations to obtain conformations that agreed with our interpretation of the cross peak observations in the ${ }^{1} \mathrm{H}-{ }^{1} \mathrm{H} 2 \mathrm{D}$ NOESY and ROESY NMR spectral data. One simulation was run for 10,000 iterations and then energy minimized using an MMFF94 energy minimization calculation using 500 iterations with a RMS gradient of 0.001 to achieve conformation C in Figure S12C. Conformations D-H in Figure S12 were generated by rotating bonds to achieve the desired conformation followed by an energy minimization using 20-50 iterations and an RMS gradient of 0.1. A table of structural parameters such as selected distances between hydrogen atoms within the conformations and energies calculated for the 3D conformations can be found in the Supporting Information section.

Electrochemistry Methods. All electrochemistry was performed on a $\mathrm{CHI} 750 \mathrm{D}$ potentiostat. For the cyclic voltammetry (CV), a classical three electrode system was used with scan rate of $100 \mathrm{mV} / \mathrm{s}$ at $22{ }^{\circ} \mathrm{C}$. The working electrode was a glassy carbon electrode (BASi MF2012, $3 \mathrm{~mm}$ ), and the counter electrode was a platinum wire electrode (BASi MW1032). The $\mathrm{Ag}^{+} / \mathrm{Ag}$ reference electrode (BASi MW1085) was constructed by inserting a $\mathrm{Ag}$ wire into a freshly prepared solution of organic solvent $\left(\mathrm{CH}_{3} \mathrm{CN}\right.$, DMSO, or pyridine) with $0.1 \mathrm{M}$ TBAP and 0.01 $\mathrm{M} \mathrm{AgNO}_{3}$. Detailed experimental, instrumentation, and analysis are available in the Supporting Information.

Langmuir Monolayer Compression Isotherms. The subphase for each experiment consisted of approximately $50 \mathrm{~mL}$ of a $20 \mathrm{mM}$ sodium phosphate buffer ( $\mathrm{pH}$ 7.4). The phospholipid solution was prepared by dissolving powdered phospholipid into a chloroform:methanol $(9: 1, \mathrm{v}: \mathrm{v})$ solution to produce $1 \mathrm{mM}$ phospholipid stock solution. The film applied to the subphase consisted of $20 \mu \mathrm{L}$ of phospholipid stock solution or a 50:50 mole fraction mixture of MK-2 with either DPPC or DPPE. The resulting film was equilibrated for $15 \mathrm{~min}$ and then compressed using a Teflon ribbon at a rate of $10 \mathrm{~mm} / \mathrm{min}\left(2.4 \AA^{2} /\right.$ chain). The surface pressure was measured using the Wilhemy plate method where a wire probe was used as the plate on a Kibron $\mu$ Trough XS. ${ }^{94}$ The reported compression isotherms are reported as an average of three trials (constructed by averaging the three isotherms in excel). See Supporting Information for compression modulus data and interpretation.

Sample Preparation for RM NMR Spectroscopic Studies. A $0.50 \mathrm{M}$ AOT stock solution was made by dissolving AOT ( $5.56 \mathrm{~g}, 12.5$ $\mathrm{mmol})$ in isooctane $(25.0 \mathrm{~mL})$. RMs were prepared by mixing the 0.50 M AOT stock solution with $\mathrm{D}_{2} \mathrm{O}(\mathrm{pH}$ 7.0) and then vortexed until clear. MK-2 RMs were made in a similar manner except an $11.2 \mathrm{mM} \mathrm{MK-2}$ stock solution was prepared by directly dissolving MK-2 in the $0.50 \mathrm{M}$ AOT/isooctane solution. Then, the MK-2-AOT-isooctane stock solution along with $\mathrm{D}_{2} \mathrm{O}(\mathrm{pH} 7)$ were used to make RMs.

1D ${ }^{1} \mathrm{H}$ NMR Spectroscopic Studies of AOT/Isooctane RMs That Contain MK-2. 1D ${ }^{1} \mathrm{H}$ NMR spectroscopic experiments were carried out using a Varian Inova $400 \mathrm{MHz}$ instrument using routine parameters (pulse angle: $45^{\circ}$, relaxation delay of $1 \mathrm{~s}$ ) at $22^{\circ} \mathrm{C}$. The RM spectra were internally referenced using the isooctane methyl peak set to 0.904 ppm. ${ }^{95}$ Data analysis and spectrum workup were done using the NMR software, MestReNova version 10.0.1.

Sample Preparation for ${ }^{1} \mathrm{H}-{ }^{1} \mathrm{H}$ 2D NOESY and ROESY NMR Spectroscopic Studies (RMs). To prepare the AOT/isooctane stock solution, $0.22 \mathrm{~g}$ AOT $(0.50 \mathrm{mmol})$ was dissolved into isooctane $(1.0$ $\mathrm{mL}$ ) for a final $0.50 \mathrm{M}$ AOT stock solution. Then $0.035 \mathrm{~g}(1.10 \mathrm{mmol})$ of MK-2 was dissolved into the $0.50 \mathrm{M}$ AOT stock solution for a final concentration of $110 \mathrm{mM} \mathrm{MK}-2$. Then, $892.6 \mu \mathrm{L}$ of MK-2 AOT/ isooctane stock solution was mixed with $107.3 \mu \mathrm{L}$ of $\mathrm{D}_{2} \mathrm{O}(\mathrm{pH}=7)$ and then vortexed until clear. This final mixture results in a $w_{0} 12 \mathrm{RM}$ microemulsion with an overall concentration of MK-2 being $100 \mathrm{mM}$ ( 29 molecules per RM).

${ }^{1} \mathrm{H}-{ }^{1} \mathrm{H}$ 2D NOESY and ROESY NMR Spectroscopic Studies in AOT/Isooctane $w_{0} 12$ RM. 2D NMR samples were ran using similar conditions used previously ${ }^{61}$ using a Varian model MR400 $400 \mathrm{MHz}$ magnet at $26{ }^{\circ} \mathrm{C}$. A standard NOESY pulse sequence was used consisting of 256 transients with 16 scans in the $\mathrm{f} 1$ direction using a 200 $\mathrm{ms}$ mixing time, $45^{\circ}$ pulse angle, and a relaxation delay of $1.5 \mathrm{~s}$. A standard ROESYAD pulse sequence was used consiting of 256 transients with 16 scans in the $\mathrm{f} 1$ direction using a $200 \mathrm{~ms}$ mixing time, $45^{\circ}$ pulse angle, and a relaxation delay of $2.0 \mathrm{~s}$. The NMR was locked onto $10 \% \mathrm{D}_{2} \mathrm{O}$, and the spectrum was referenced to the isooctane methyl peak at $0.904 \mathrm{ppm}$ as previously reported. ${ }^{95}$ The resulting spectrum was processed using MestReNova NMR software version 10.0.1. The 3D structure illustration within a $\mathrm{RM}$ was drawn using 
ChemBioD Ultra 12.0 and ChemBio3D Ultra 12.0 based on spectral parameters described under results.

\section{ASSOCIATED CONTENT}

\section{S Supporting Information}

The Supporting Information is available free of charge on the ACS Publications website at DOI: 10.1021/acs.joc.7b02649.

General experimental information; $1 \mathrm{D}$ and 2D NMR spectroscopic and structural data of MK-2, MK-2 conformational analysis, and relevant internuclear distances; electrochemistry experimental and data/discussion; ${ }^{1} \mathrm{H}$ NMR of MK-2 with TBAP; Langmuir monolayer compression modulus of MK-2 and interpretation (PDF)

\section{AUTHOR INFORMATION}

\section{Corresponding Author}

*E-mail: Debbie.Crans@colostate.edu

\section{ORCID}

Jordan T. Koehn: 0000-0003-3008-6303

Debbie C. Crans: 0000-0001-7792-3450

\section{Notes}

The authors declare no competing financial interest.

\section{ACKNOWLEDGMENTS}

Drs. Crans and Crick thank NIH for funding (grant no. AI119567) and the NSF for funding (grant no. CHE-1709564). Dr. Crans also thanks the Arthur Cope Foundation administered by the American Chemical Society for partial support.

\section{REFERENCES}

(1) Beller, H. R.; Soon Lee, T.; Katz, L. Nat. Prod. Rep. 2015, 32, 1508.

(2) Frank, A.; Groll, M. Chem. Rev. 2017, 117, 5675.

(3) Thulasiram, H. V.; Erickson, H. K.; Poulter, C. D. Science 2007, $316,73$.

(4) da Costa, M. S.; Albuquerque, L.; Nobre, M. F.; Wait, R. In Methods in Microbiology: Taxonomy of Prokaryotes; Rainey, F., Oren, A., Eds.; Elsevier Academic Press Inc: San Diego, CA, 2011; Vol. 38, p 197.

(5) Kroppenstedt, R. M.; Mannheim, W. Int. J. Syst. Bacteriol. 1989, 39, 304.

(6) Collins, M. D.; Jones, D. Microbiol. Rev. 1981, 45, 316.

(7) Meganathan, R. Vitam. Horm. 2001, 61, 173.

(8) Caluwe, R.; Pyfferoen, L.; De Boeck, K.; De Vriese, A. S. Clin. Kidney J. 2016, 9, 273.

(9) Bergdoll, L.; ten Brink, F.; Nitschke, W.; Picot, D.; Baymann, F. Biochim. Biophys. Acta, Bioenerg. 2016, 1857, 1569.

(10) Epand, R. M.; Walker, C.; Epand, R. F.; Magarvey, N. A. Biochim. Biophys. Acta, Biomembr. 2016, 1858, 980.

(11) Villaume, M. T.; Sella, E.; Saul, G.; Borzilleri, R. M.; Fargnoli, J.; Johnston, K. A.; Zhang, H.; Fereshteh, M. P.; Murali Dhar, T. G.; Baren, P. S. ACS Cent. Sci. 2016, 2, 27.

(12) Choi, S. R.; Larson, M. A.; Hinrichs, S. H.; Bartling, A. M.; Frandsen, J.; Narayanasamy, P. Future Med. Chem. 2016, 8, 11.

(13) Matarlo, J. S.; Lu, Y.; Daryaee, F.; Daryaee, T.; Ruzsicska, B.; Walker, S. G.; Tonge, P. J. ACS Infect. Dis. 2016, 2, 329.

(14) Szamosvari, D.; Bottcher, T. Angew. Chem., Int.Ed. 2017, 56, 7271.

(15) Vilcheze, C.; Hartman, T.; Weinrick, B.; Jain, P.; Weisbrod, T. R.; Leung, L. W.; Freundlich, J. S.; Jacobs, W. R. Proc. Natl. Acad. Sci. U. S. A. 2017, 114, 4495.

(16) Upadhyay, A.; Fontes, F. L.; Gonzalez-Juarrero, M.; McNeil, M. R.; Crans, D. C.; Jackson, M.; Crick, D. C. ACS Cent. Sci. 2015, 1, 292. (17) Vos, M.; Esposito, G.; Edirisinghe, J. N.; Vilain, S.; Haddad, D. M.; Slabbaert, J. R.; Van Meensel, S.; Schaap, O.; De Strooper, B.; Meganathan, R.; Morais, V. A.; Verstreken, P. Science 2012, 336, 1306.
(18) Nakagawa, K.; Hirota, Y.; Sawada, N.; Yuge, N.; Watanabe, M.; Uchino, Y.; Okuda, N.; Shimomura, Y.; Suhara, Y.; Okano, T. Nature 2010, 468, 117.

(19) Hiratsuka, T.; Furihata, K.; Ishikawa, J.; Yamashita, H.; Itoh, N.; Seto, H.; Dairi, T. Science 2008, 321, 1670.

(20) Newman, D. K.; Kolter, R. Nature 2000, 405, 94.

(21) Collins, M. D.; Shah, H. N.; Minnikin, D. E. J. Appl. Bacteriol. 1980, 48, 277.

(22) Thomson, R. H. Naturally Occurring Quinones; Chapman \& Hall: London, 1971.

(23) Cooper, G. M.; Hausman, R. E. The Cell: A Molecular Approach, 5th ed.; Sinauer Associates, Inc.: Sunderland, MA, 2009.

(24) Nelson, D. L.; Cox, M. M. Lehninger Principles of Biochemistry, 5th ed.; W. H. Freeman and Company: New York, 2008.

(25) Woodward, R. B.; Bloch, K. J. Am. Chem. Soc. 1953, 75, 2023.

(26) Hess, B. A., Jr.; Smentek, L. Angew. Chem., Int. Ed. 2013, 52, 11029.

(27) Murgolo, N. J.; Patel, A.; Stivala, S. S.; Wong, T. K. Biochemistry $1989,28,253$.

(28) Lowry, T. H.; Richardson, K. S. Mechanism and Theory in Organic Chemistry, 3rd ed.; Harper \& Row Publishers: New York, 1987.

(29) Klauda, J. B.; Brooks, B. R.; et al. J. Phys. Chem. B 2005, 109, 5300.

(30) Choudhury, R.; Barman, A.; Prabhakar, R.; Ramamurthy, V. J. Phys. Chem. B 2013, 117, 398.

(31) Chum, S. P.; Knight, G. W.; Ruiz, J. M.; Phillips, P. J. Macromolecules 1994, 27, 656.

(32) Robertson, M. B.; Klein, P. G.; Ward, I. M.; Packer, K. J. Polymer 2001, 42, 1261.

(33) Cao, M.; Monson, P. A. J. Phys. Chem. B 2009, 113, 13866.

(34) Nikki, K.; Inakura, H.; Wu-Le; Suzuki, N.; Endo, T. J. Chem. Soc., Perkin Trans. 2 2001, 2370.

(35) Nikki, K.; Nakagawa, N. Org. Magn. Reson. 1983, 21, 552.

(36) Nikki, K. Magn. Reson. Chem. 1990, 28, 385.

(37) Law, J. M. S.; Setiadi, D. H.; Chass, G. A.; Csizmadia, I. G.; Viskolcz, B. J. Phys. Chem. A 2005, 109, 520.

(38) Kanicky, J. R.; Shah, D. O. J. Colloid Interface Sci. 2002, 256, 201.

(39) Ko, Y. H.; Kim, Y.; Kim, H.; Kim, K. Chem. - Asian J. 2011, 6, 652.

(40) Ko, Y. H.; Kim, H.; Kim, Y.; Kim, K. Angew. Chem., Int. Ed. 2008, 47, 4106.

(41) Schramm, M. P.; Rebek, J., Jr. Chem. - Eur. J. 2006, 12, 5924.

(42) de Sousa, F. F.; Freire, P. T. C.; Saraiva, G. D.; Lima, J. A.; Alcantara, P.; Melo, F. E. A.; Mendes, J. Vib. Spectrosc. 2010, 54, 118.

(43) Collins, M. D.; Kroppenstedt, R. M. FEMS Microbiol. Lett. 1987, $44,215$.

(44) Bentley, R. Pure Appl. Chem. 1975, 41, 47.

(45) Suhara, Y.; Wada, A.; Tachibana, Y.; Watanabe, M.; Nakamura, K.; Nakagawa, K.; Okano, T. Bioorg. Med. Chem. 2010, 18, 3116.

(46) Payne, R. J.; Daines, A. M.; Clark, B. M.; Abell, A. D. Bioorg. Med. Chem. 2004, 12, 5785.

(47) Tynkkynen, T.; Hassinen, T.; Tiainen, M.; Soininen, P.; Laatikainen, R. Magn. Reson. Chem. 2012, 50, 598.

(48) Ishihara, M.; Sakagami, H. Anticancer Res. 2007, 27, 4059.

(49) Lancaster, C. R. D.; Haas, A. H.; Madej, M. G.; Mileni, M. Biochim. Biophys. Acta, Bioenerg. 2006, 1757, 988.

(50) Prince, R. C.; Leslie Dutton, P.; Malcolm Bruce, J. FEBS Lett. 1983, 160, 273.

(51) Guin, P. S.; Das, S.; Mandal, P. C. Int. J. Electrochem. 2011, 2011, 816202 .

(52) Dryhurst, G., Kadish, K. M., Scheller, F., Renneberg, R. Biological Eletrochemistry; Academic Press: New York, 1982.

(53) Luder, W. F.; Kraus, P. B.; Kraus, C. A.; Fuoss, R. M. J. Am. Chem. Soc. 1936, 58, 255.

(54) Jaworski, J. S.; Leniewska, E.; Kalinowski, M. K. J. Electroanal. Chem. Interfacial Electrochem. 1979, 105, 329.

(55) Baruah, B.; Roden, J. M.; Sedgwick, M.; Correa, N. M.; Crans, D. C.; Levinger, N. E. J. Am. Chem. Soc. 2006, 128, 12758.

(56) Odella, E.; Falcone, R. D.; Silber, J. J.; Correa, N. M. ChemPhysChem 2016, 17, 2407. 
(57) Diaz-Fernandez, Y.; Foti, F.; Mangano, C.; Pallavicini, P.; Patroni, S.; Perez-Gramatges, A.; Rodriguez-Calvo, S. Chem. - Eur. J. 2006, 12, 921.

(58) Pallavicini, P.; Diaz-Fernandez, Y.; Pasotti, L. Coord. Chem. Rev. 2009, 253, 2226.

(59) Stefaniu, C.; Brezesinski, G.; Mohwald, H. Adv. Colloid Interface Sci. 2014, 208, 197.

(60) Sostarecz, A. G.; Gaidamauskas, E.; Distin, S.; Bonetti, S. J.; Levinger, N. E.; Crans, D. C. Chem. - Eur. J. 2014, 20, 5149.

(61) Peters, B. J.; Groninger, A. S.; Fontes, F. L.; Crick, D. C.; Crans, D. C. Langmuir 2016, 32, 9451.

(62) Riter, R. E.; Kimmel, J. R.; Undiks, E. P.; Levinger, N. E. J. Phys. Chem. B 1997, 101, 8292.

(63) Maitra, A. J. Phys. Chem. 1984, 88, 5122.

(64) Durantini, A. M.; Falcone, R. D.; Silber, J. J.; Correa, N. M. ChemPhysChem 2016, 17, 1678.

(65) Lepori, C. M. O.; Correa, N. M.; Silber, J. J.; Falcone, R. D. Soft Matter 2016, 12, 830.

(66) Hoyo, J.; Torrent-Burgues, J.; Guas, E. J. Colloid Interface Sci. 2012, 384, 189.

(67) Quinn, P. J.; Esfahani, M. A. Biochem. J. 1980, 185, 715.

(68) Patterson, M.; Vogel, H. J.; Prenner, E. J. Biochim. Biophys. Acta, Biomembr. 2016, 1858, 403.

(69) Roche, Y.; Peretti, P.; Bernard, S. J. Therm. Anal. Calorim. 2007, $89,867$.

(70) De, T. K.; Maitra, A. Adv. Colloid Interface Sci. 1995, 59, 95.

(71) Sedgwick, M. A.; Trujillo, A. M.; Hendricks, N.; Levinger, N. E.; Crans, D. C. Langmuir 2011, 27, 948.

(72) Zan, G. T.; Wu, Q. S. Adv. Mater. 2016, 28, 2099.

(73) Kuchler, A.; Yoshimoto, M.; Luginbuhl, S.; Mavelli, F.; Walde, P. Nat. Nanotechnol. 2016, 11, 409.

(74) Dharaiya, N.; Bahadur, P. Colloids Surf., A 2012, 410, 81.

(75) Dumas, C.; Meledandri, C. J. Langmuir 2015, 31, 7193.

(76) Kaur, G.; Chiappisi, L.; Prevost, S.; Schweins, R.; Gradzielski, M.; Mehta, S. K. Langmuir 2012, 28, 10640.

(77) Sanchez-Lombardo, I.; Baruah, B.; Alvarez, S.; Werst, K. R.; Segaline, N. A.; Levinger, N. E.; Crans, D. C. New J. Chem. 2016, 40, 962.

(78) Crans, D. C.; Levinger, N. E. Acc. Chem. Res. 2012, 45, 1637.

(79) Bock, C. W.; Panchenko, Y. N.; Krasnoshchiokov, S. V.; Aroca, R. J. Mol. Struct. 1987, 160, 337.

(80) Squillacote, M. E.; Semple, T. C.; Mui, P. W. J. Am. Chem. Soc. $1985,107,6842$.

(81) Mui, P. W.; Grunwald, E. J. Phys. Chem. 1984, 88, 6340.

(82) Gundersen, G.; Thomassen, H. G.; et al. J. Mol. Struct. 1991, 243, 385.

(83) Fujimoto, N.; Kosaka, T.; Yamada, M. Menaquinone as Well as Ubiquinone as a Crucial Component in the Escherichia coli Respiratory Chain; InTech: Rijeka, Croatia, 2012.

(84) Lai, C.-T.; Li, H.-J.; Yu, W.; Shah, S.; Bommineni, G. R.; Perrone, V.; Garcia-Diaz, M.; Tonge, P. J.; Simmerling, C. Biochemistry 2015, 54, 4683.

(85) Yano, T.; Rahimian, M.; Aneja, K. K.; Schechter, N. M.; Rubin, H.; Scott, C. P. Biochemistry 2014, 53, 1179.

(86) Peover, M. E. J. Chem. Soc. 1962, 4540.

(87) Chadar, D.; Camilles, M.; Patil, R.; Khan, A.; Weyhermuller, T.; Salunke-Gawali, S. J. Mol. Struct. 2015, 1086, 179.

(88) Kathawate, L.; Joshi, P. V.; Dash, T. K.; Pal, S.; Nikalje, M.; Weyhermuller, T.; Puranik, V. G.; Konkimalla, V. B.; Salunke-Gawali, S. J. Mol. Struct. 2014, 1075, 397.

(89) McQuaw, C. M.; Sostarecz, A. G.; Zheng, L.; Ewing, A. G.; Winograd, N. Langmuir 2005, 21, 807.

(90) Demel, R. A.; Geurts Van Kessel, W. S. M.; Zwaal, R. F. A.; Roelofsen, B.; Van Deenen, L. M. Biochim. Biophys. Acta, Biomembr. 1975, 406, 97.

(91) Choi, Y.; Attwood, S. J.; Hoopes, M. I.; Drolle, E.; Karttunen, M.; Leonenko, Z. Soft Matter 2014, 10, 206.

(92) Belzile, M.-N.; Godin, R.; Durantini, A.; Cosa, G. J. Am. Chem. Soc. 2016, 138, 16388.
(93) Dobrinescu, C.; Iorgulescu, E. E.; Mihailciuc, C.; Macovei, D.; Wuttke, S.; Kemnitz, E.; Parvulescu, V. I.; Coman, S. M. Adv. Synth. Catal. 2012, 354, 1301.

(94) Girard-Egrot, A.; Blum, L. J. Langmuir-Blodgett Technique for Synthesis of Biomimetic Lipid Membranes. In Nanobiotechnology of Biomimetic Membranes; Ferrari, M., Martin, D. K., Eds.; Springer: New York, 2007; p 23.

(95) Samart, N.; Beuning, C. N.; Haller, K. J.; Rithner, C. D.; Crans, D. C. Langmuir 2014, 30, 8697. 